\title{
Genetic analysis of water loss of excised leaves associated with drought tolerance in wheat
}

Ilona Mieczysława Czyczyło-Mysza ${ }^{\text {Corresp., }}{ }^{1}$ ， Izabela Marcińska ${ }^{1}$ ， Edyta Skrzypek ${ }^{1}$ ， Jan Bocianowski ${ }^{2}$, Kinga Dziurka $^{1}{ }^{\text {, }}$ Dragana Rančić ${ }^{3}$, Radenko Radošević ${ }^{3}$, Sofija Pekić-Quarrie ${ }^{3}$, Dejan Dodig ${ }^{4}$, Stephen Alexander Quarrie $^{5}$

${ }^{1}$ Department of Biotechnology, Polish Academy of Sciences The Franciszek Górski Institute of Plant Physiology, Kraków, Poland

2 Department of Mathematical and Statistical Methods, Poznań University of Life Sciences, Poznań, Poland

3 Faculty of Agriculture, University of Belgrade, Belgrade, Serbia

${ }^{4}$ Maize Research Institute Zemun Polje, Serbia

${ }^{5}$ Newcastle University Business School, Newcastle upon Tyne, United Kingdom

Corresponding Author: llona Mieczysława Czyczyło-Mysza

Email address: czyczylo-mysza@wp.pl

Background. Wheat is widely affected by drought. Low excised-leaf water loss (ELWL) has frequently been associated with improved grain yield under drought. This study dissected the genetic control of ELWL in wheat, associated physiological, morphological and anatomical leaf traits, and compared these with yield QTLs. Methods. Ninety four hexaploid wheat (Triticum aestivum L.) doubled haploids, mapped with over 700 markers, were tested for three years for ELWL from detached leaf 4 of glasshouse-grown plants. In one experiment, stomata per unit area and leaf thickness parameters from leaf crosssections were measured. QTLs were identified using QTLCartographer. Results. ELWL was significantly negatively correlated with leaf length, width, area and thickness. Major QTLS for ELWL during $0-3 \mathrm{~h}$ and 3-6 $\mathrm{h}$ were coincident across trials on $3 \mathrm{~A}, 3 \mathrm{~B}, 4 \mathrm{~B}, 5 \mathrm{~B}, 5 \mathrm{D}, 6 \mathrm{~B}$, 7A, 7B, 7D and frequently coincident (inversely) with leaf size QTLs. Yield in other trials was sometimes associated with ELWL and leaf size phenotypically and genotypically, but more frequently under non-droughted than droughted conditions. QTL coincidence showed only ELWL to be associated with drought/control yield ratio. Discussion. Our results demonstrated that measures of ELWL and leaf size were equally effective predictors of yield, and both were more useful for selecting under favourable than stressed conditions. 
1

2

3 I. M. Czyczyło-Mysza1*, I. Marcińska1 ${ }^{1}$, E. Skrzypek¹, J. Bocianowski², K. Dziurka1 ${ }^{1}$, D. Rančić ${ }^{3}$,

4 R. Radošević ${ }^{3}$, S. Pekić-Quarrie ${ }^{3}$, D. Dodig 4 , S.A. Quarrie ${ }^{5,6}$

$5{ }^{1}$ Polish Academy of Sciences The Franciszek Górski Institute of Plant Physiology, Krakow,

6 Poland

72 Poznań University of Life Sciences, Department of Mathematical and Statistical Methods,

8 Poznań, Poland

$9{ }^{3}$ Faculty of Agriculture, Belgrade University, Nemanjina 6, 11081 Belgrade-Zemun, Serbia 10

11 Serbia

12

\section{Genetic analysis of water loss of excised leaves associated with drought tolerance} in wheat

${ }^{4}$ Maize Research Institute Zemun Polje, 1 Slobodana Bajića Street, 11185 Zemun-Belgrade,

${ }^{5}$ Faculty of Biology, Belgrade University, Studentski trg 16, 11000 Belgrade, Serbia

${ }^{6}$ Newcastle University Business School, 5 Barrack Road, Newcastle upon Tyne, NE1 4SE

* Corresponding author: tel. (048) 124251833, e-mail czyczylo-mysza@wp.pl 


\section{Abstract}

Wheat is widely affected by drought. Low excised-leaf water loss (ELWL) has frequently been associated with improved grain yield under drought. This study dissected the genetic control of ELWL in wheat, associated physiological, morphological and anatomical leaf traits, and compared these with yield QTLs. Ninety four hexaploid wheat (Triticum aestivum L.) doubled haploids, mapped with over 700 markers, were tested for three years for ELWL from detached leaf 4 of glasshouse-grown plants. In one experiment, stomata per unit area and leaf thickness parameters from leaf cross-sections were measured. QTLs were identified using QTLCartographer. ELWL was significantly negatively correlated with leaf length, width, area and thickness. Major QTLs for ELWL during 0-3 h and 3-6 h were coincident across trials on 3A, 3B, 4B, 5B, 5D, 6B, 7A, 7B, 7D and frequently coincident (inversely) with leaf size QTLs. Yield in other trials was sometimes associated with ELWL and leaf size phenotypically and genotypically, but more frequently under non-droughted than droughted conditions. QTL coincidence showed only ELWL to be associated with drought/control yield ratio. Our results demonstrated that measures of ELWL and leaf size were equally effective predictors of yield, and both were more useful for selecting under favourable than stressed conditions.

\section{Introduction}

Wheat (Triticum aestivum L.) is grown worldwide under diverse climatic conditions. Drought is a significant factor restricting wheat production, affecting large areas in both developing and developed countries. Climate change is predicted to reduce rainfall during wheat reproductive development and grain filling in many countries, so a frequent target for wheat breeders is improving drought tolerance. The influence of water availability on plant productivity suggests that water limitation has shaped the natural variation and evolution of many physiological traits (Dudley, 1996).

Many traits have been considered for drought tolerancescreening (e.g. Foulkes et al., 2007; Reynolds et al., 2007; Monneveux et al., 2012). A physiological trait often used as a selection criterion for improving drought toleranceis rate of leaf water loss. This has been studied in wheat since 1937 (Bayles et al., 1937), and in excised wheat leaves since 1969 (Salim et al., 1969) as a technique for measuring drought avoidance in cereal seedlings. Since then, excised-leaf water 
49 loss (ELWL) in wheat has been used extensively as a selection tool indicating drought tolerance 50 (for example Dedio, 1975; Kirkham et al., 1980; Clarke \& McCaig, 1982b; Winter et al., 1988; 51 Yang et al., 1991; Dhanda \& Sethi, 1998; Golestani Araghi \& Assad, 1998; Chandra \& Islam, 52 2003; David, 2010). Thus, rate of water loss from excised leaves has been negatively associated 53 with grain yield under drought in wheat in many reports (e.g. Clarke \& McCaig, 1982a; Clarke 54 \& Townley-Smith, 1986; Clarke et al., 1989; Haley et al., 1993; Chandra \& Islam, 2003). 55 Excised-leaf water loss was found to be heritable and predominantly controlled by additive gene 56 effects (Clarke \& Townley-Smith, 1986; Dhanda \& Sethi, 1998; Chandra \& Islam, 2003).

The availability of molecular marker technologies provides opportunities to dissect the genetic control of physiological traits, and gives breeders access to quantitative trait loci (QTLs) for traits suitable for introgression to improve varieties. A detailed analysis of the genetic control of ELWL in bread wheat has not yet been fully reported, though in preliminary results, Yang's group (Yang et al., 2009; Mei, 2012) identified QTLs for rate of excised-leaf water loss in two wheat recombinant inbred line populations.

Thus, the primary aims of this study were to dissect the genetic control of excised-leaf water loss using a well-characterised wheat mapping population of doubled haploid lines from the cross Chinese Spring $\times$ SQ1 (Quarrie et al., 2005; 2006; Habash et al., 2007; CzyczyłoMysza et al., 2013), and to identify leaf parameters likely to determine genetic variation in ELWL.

Yield has been recorded in this mapping population in over 50 treatment $\times$ site $\times$ year occasions including 12 trials where drought treatments caused significant reductions of yield. Additionally, therefore, phenotypic and genetic associations of yield with both ELWL and several leaf parameters were also compared. The value of ELWL as a selection criterion for improving yield in wheat under drought stress is questioned.

\section{Materials and Methods}

Plant material

The mapping population consisted of 94 doubled haploid lines (CSDH) from the cross between hexaploid wheat (Triticum aestivum L.) genotypes Chinese Spring (CS) and SQ1 (a breeding line) according to Quarrie et al. (2005) and available from the John Innes Centre, Norwich (mike.ambrose@bbsrc.ac.uk). 
80

81

82

108

109

110

111

\section{Excised leaf dehydration}

Excised-leaf water loss in the CSDH population was determined using the procedure of Clarke \& McCaig (1982a). After six weeks vernalization at $4^{\circ} \mathrm{C}$, plants were grown under well-watered conditions in a temperature-controlled glasshouse until leaf 4 ligule emerged. This leaf was then detached, quickly transferred to a nearby walk-in growth chamber maintained at $20^{\circ} \mathrm{C}, 50 \%$ relative humidity and continuous light of $250 \mu \mathrm{mol} \mathrm{m}^{-2} \mathrm{~s}^{-1}$ (HPS “Agro" lamps, Osram), placed on a v-shaped card support (Figure S1) and water loss monitored. Leaf weights were recorded immediately $(0 \mathrm{~h})$, after 3 and $6 \mathrm{~h}$ and finally after drying at $70^{\circ} \mathrm{C}$ for $48 \mathrm{~h}$.

The mapping population was tested three times (experiment I, II and III) under ostensibly identical conditions in the growth chamber in consecutive years (2007-2009), with three replicate leaves sampled per CSDH line on each occasion.

ELWL after $3 \mathrm{~h}, 6 \mathrm{~h}$ and from 3 to $6 \mathrm{~h}$ was calculated as water loss per unit initial water content (ELWLW), according to Clarke \& McCaig (1982a) as follows

(1) $\left.\mathrm{ELWLW}_{0-3 \mathrm{~h}}=\underline{\mathrm{FW}}_{0}-\mathrm{FW}_{3}\right)$, $\left(\mathrm{FW}_{0}-\mathrm{DW}\right)$

(2) $\mathrm{ELWLW}_{3-6 \mathrm{~h}}=\left(\mathrm{FW}_{3}-\mathrm{FW}_{6}\right)$, $\left(\mathrm{FW}_{3}-\mathrm{DW}\right)$

(3) $\left.\mathrm{ELWLW}_{0-6 \mathrm{~h}}=\underline{(\mathrm{FW}}_{0}-\mathrm{FW}_{6}\right)$ $\left(\mathrm{FW}_{0}-\mathrm{DW}\right)$

where: $\mathrm{FW}_{0}, \mathrm{FW}_{3}$ and $\mathrm{FW}_{6}$ are fresh weight after 0,3 and $6 \mathrm{~h}$, respectively, and $\mathrm{DW}$ is dry weight after drying at $70^{\circ} \mathrm{C}$.

Leaf length and width were measured before dehydration to estimate leaf surface area (LA) as length $\times$ width $\times 0.78$ : a factor previously determined to be appropriate for wheat leaf four (Quarrie \& Jones, 1977). From this, rate of water loss $/ \mathrm{cm}^{2}$ (ELWLA) during the first $3 \mathrm{~h}, 3-6 \mathrm{~h}$ and $6 \mathrm{~h}$ of excision was calculated as for equations (1)-(3), substituting LA for water content, as well as initial leaf $\mathrm{FW} / \mathrm{cm}^{2}$.

As ELWL has also been expressed in the literature on the basis of initial leaf FW or DW, ELWL on the basis of FW (ELWLF) and DW (ELWLD) were calculated (substituting FW-DW in equations (1) to (3) with $\mathrm{FW}_{0}$ or DW, respectively).

\section{Leaf morphological and anatomical measurements}


112 In experiment (III), prior to dehydration the basal $c a .2 \mathrm{~cm}$ of each leaf 4 was cut and placed into

$11370 \%$ ethanol solution. Leaf cross-sections were prepared manually, and analysed on a 114 microscope slide under a bright-light microscope at $\times 5$ magnification. Sections were 115 photographed with a digital camera (LEICA DC 300) and leaf thickness measured at the midrib 116 and along the lamina: two measurements in the "valley" between two secondary vascular 117 bundles and two measurements at the thickest part across vascular bundles on each side of the 118 midrib. Thus, CSDH line mean midrib thickness and lamina thickness were based on three 119 measurements at the midrib and 24 measurements across the lamina [3 leaves $\times(4$ maximum 120 widths +4 minimum widths)].

121 Leaf segments were also examined directly at $\times 10$ magnification to count stomata per field 122 of view $\left(0.761 \mathrm{~mm}^{2}\right)$. Two fields of view either side of the midrib on the lower leaf surface were 123 selected randomly on each leaf segment.

Grain yield from field and pot trials

126 Grain yield per plant from field trials with 95 CSDH lines in Norwich, UK in 1997 and 1998 127 (mean of five random plants per CSDH line) were described in Quarrie et al. (2005), and in 128 Zaječar, Serbia in 2000, 2001 and 2002 (yield and plant number per row) were described in 129 Quarrie et al. (2005, 2006). Grain yield per plant from pot trials in Krakow, Poland in 2007, 130 2008, 2010 and 2011 with irrigated and droughted treatments were described in Czyczyło-Mysza 131 et al. (2013) and Czyczyło-Mysza (2013).

132 Further yield trials were carried out in the field in Zaječar in 2004-2005 and 2005-2006, 133 with plants grown from autumn sowings (30th October, 2004 and 14 ${ }^{\text {th }}$ November, 2005, 134 respectively) as described for previous years in Quarrie et al. (2005), with two treatments. Two 135 replicate plots were rainfed and two replicate plots were covered with a rain-out shelter at the 136 beginning of tillering, from $4^{\text {th }}(2005)$ and $5^{\text {th }}$ (2006) April, as described in Dodig et al. (2002).

137 The shelter stayed over droughted plots until maturity and reduced light intensity by around $13850 \%$.

139 Pot trials with $94 \mathrm{CSDH}$ lines were carried out in Krakow in 2006, with seedlings 140 transferred to a glasshouse (three plants per line) with or without vernalisation, as described in 141 Czyczyło-Mysza et al. (2013). Only the main ear was sampled for grain weight. Two other trials, 142 under the same conditions described for 2010 and 2011 by Czyczyło-Mysza et al. (2013), were 
143 carried out in 2012 and 2013. Yield per plant was recorded in irrigated and droughted treatments

144 with three replicate plants per CSDH line and treatment.

145 Grain yield per plant was also measured in the following trials. In 1994, all CSDH lines

146 were multiplied in the field from a spring sowing with one row per line at Morley Experimental

147 Station, Norfolk, UK, and in a soil glasshouse trial at the John Innes Centre, Norwich, UK using

$14873 \mathrm{CSDH}$ lines. Spring-sown plants, one row per CSDH line in two replicate plots, were watered

149 until $16^{\text {th }}$ May and then again from $6^{\text {th }}$ July, to give a drought stress during flowering and early

150 grain filling. Field trials with $95 \mathrm{CSDH}$ lines were sown in the autumn with two replicate plots of

151 three rows per CSDH line in 2002-3 and 2003-4 in Conselice and Idice, northern Italy, organised

152 by Società Italiana Sementi Spa (Ravaglia, 2005). The ozone fumigation trial of 2003 using 153 open-top chambers at Newcastle University's Close House Experimental Station, UK (Quarrie et 154 al., 2006) included two additional ozone fumigation treatments not reported in Quarrie et al.

155 (2006), of nominally $25 \mathrm{ppb}$ and $50 \mathrm{ppb}$, with four chambers per treatment and one pot with 156 three plants per CSDH line in each chamber. The Close House ozone fumigation trial was 157 repeated in 2005, with non-filtered air (NFA) and NFA plus 50 ppb ozone treatments. Plants 158 were grown and treated exactly as described in Quarrie et al. (2006), except that ozone 159 fumigation began $8 \mathrm{~d}$ earlier, during the rapid tillering phase.

160 In total, these 52 year $\times$ site $\times$ treatment trials for yield per plant included 19 regarded as 161 control (little stress) and 12 where a drought treatment was the major stress, reducing yields 162 significantly, by at least $10 \%$. For these 12 trials a mean drought effect was calculated for each $163 \mathrm{CSDH}$ line as mean drought yield/mean control yield.

164 A further estimate of yield per plant for each CSDH line under favourable and stressed 165 conditions was calculated using genotype $\times$ environment plots for each line as described in 166 Quarrie et al. (2005). Linear regressions of genotype yields from the 52 trials on site mean yields 167 were used to calculate yield per plant for each CSDH line at site mean yields of 2 and $7 \mathrm{~g} / \mathrm{plant}$ 168 (equivalent to $c a .2 .5$ and $9 \mathrm{t} \mathrm{ha}^{-1}$, respectively).

Phenotypic analysis

171 Phenotypic data were analysed using GenStat v. 17, and Microsoft EXCEL ${ }^{\text {TM }}$ (trait correlations 172 and broad-sense heritabilities). Normality of distributions of CSDH means for each trait were 173 tested using the Shapiro-Wilk normality test (Shapiro \& Wilk, 1965). Two-way analysis of 
174 variance (ANOVA) was carried out for each trait to determine effects of experiments, lines and 175 experiments $\times$ lines interaction. Relationships amongst traits were calculated based on CSDH 176 line means.

177

178 QTL analysis

179 The CS $\times$ SQ1 genetic map of Czyczyło-Mysza et al. (2013), with 702 non-duplicated markers 180 (80 RFLP, 227 SSR, 81 AFLP, 292 DArT, 14 EST, 5 biochemical and 3 phenotypic markers) 181 distributed on 21 chromosomes, was slightly adjusted by replacing missing marker scores with 182 scores predicted from flanking markers, when these both had the same allele score, and 183 reanalysed to achieve the best-fit marker orders and to remove occasional order inconsistencies 184 in the Czyczyło-Mysza et al. (2013) map. This adjusted genetic map of $3640.5 \mathrm{cM}$ (Kosambi 185 mapping function) was used for QTL analysis. QTLs for CSDH line mean data in each 186 experiment were identified using single-marker analysis (SMA) with Windows 187 QTLCartographer version 2.5 (Wang et al., 2011) or QTL Cartographer v. 1.17j, 28 January 188 2005 for Macintosh, and Windows QTLCartographer was used for composite interval mapping (CIM) of ELWL and other leaf traits. A QTL from CIM was accepted when the LOD score was 190 191 greater than 2 .

To allow for trait variation from experiment to experiment and to compare QTL coincidences amongst traits on an equal scale, single marker LRmapqtl output was modified by expressing marker additive effects as ratios of the Minimum Significant Additive Effect

194

195

196

197

198

199

200

201

202

203

204 (MSAE), determined as the minimum absolute one-star [*] $P \leq 0.05$ additive effect for a particular trait and experiment. Thus, $1=$ marker additive effect equal to MSAE. Using this procedure, a marker additive-effect ratio (MAR) of one is equivalent to $P=0.05$ with LRmapqtl, and $P=0.01$, 0.001 and 0.0001 with LRmapqtl was determined to be equivalent to ratios of $c a .1 .32,1.65$ and 1.92 , respectively, with these CSDH lines.

For each trait and marker, a mean MAR was calculated as the mean of MARs from each experiment. Thus, the three-experiment mean of MARs [Method 1] was derived as:

trait 3-replicate mean $\rightarrow$ LRmapqtl $\rightarrow$ marker additive effect $\rightarrow$ additive-effect ratio $\rightarrow$ I-III

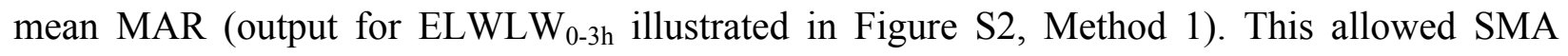
results for all traits to be compared using the same scale and facilitated graphical display. As peak additive-effect ratios for a particular trait frequently occurred at the same markers in each 
205 experiment, though not always reaching one-star (5\%) significance with LRmapqtl, the arbitrary 206 threshold of $0.5 \times$ MSAE was used for including a mean MAR for graphical presentation. SMA 207 for traits measured only in experiment III are also presented as additive-effect ratios. Positive 208 and negative MARs indicate alleles increasing the trait coming from CS (CS alleles increasing) 209 and SQ1 (SQ1 alleles increasing), respectively.

210 QTLs declared to be present using mean MARs [Method 1] were chosen to be those 211 equivalent to $P \leq 0.05$ significance using marker additive effects from LRmapqtl output for the 212 three-experiment mean ratio [Method 2], determined as follows:

213 trait 3-replicate mean $_{\mathrm{I}} \rightarrow$ trait mean $(\mathrm{I}+\mathrm{II}+\mathrm{III}) / 3 \rightarrow$ LRmapqtl $\rightarrow$ marker additive effect $\rightarrow$ MAR

214 (output for ELWLW $0-3 \mathrm{~h}$ illustrated in Figure S2, Method 2). These QTLs were characterised in 215 Table S1, and identified with arrowheads in Figures 1, 2, S2.

216 A coincidence of QTLs was assumed when SMA MAR maxima and/or CIM LOD score 217 maxima were within $10 \mathrm{cM}$, representing a minimum precision typical for QTL detection 218 (Mangin \& Goffinet, 1997).

219

220

Results

221 Phenotypic analyses

222

Phenotypic variation

223

The Shapiro-Wilk normality test showed all traits to be normally distributed in each year.

224 ANOVA showed the main effects of CSDH lines, experiments and line $\times$ experiment interactions to be significant for all traits (Table 1a,b). Multivariate analysis of variance indicated that effects of experiments (Wilk's $\lambda=0.02257 ; \mathrm{F}_{2,14}=668.25$; $\mathrm{P}<0.0001$ ), lines (Wilk's $\lambda=0.00000121$; $\left.\mathrm{F}_{93,651}=8.31 ; P<0.0001\right)$ and experiments $\times$ lines interactions (Wilk's $\lambda=0.007462 ; \mathrm{F}_{186,1302}=$ $3.00 ; P<0.0001)$ were all highly significant.

Thus, despite growing plants under ostensibly the same conditions and time of year each year, ANOVA showed highly significant genotype $\times$ year interactions for every trait (Table 1a). Leaves were generally longer in 2009 and narrower in 2007, leading to leaf areas being 44\% greater in $2009\left(18.0 \mathrm{~cm}^{2}\right)$ than in $2007\left(12.5 \mathrm{~cm}^{2}\right)$, though leaf $\mathrm{FW} / \mathrm{cm}^{2}$, a measure of leaf thickness, was only 13\% greater in 2009 than in 2007 (17.3 and $19.6 \mathrm{mg} / \mathrm{cm}^{2}$, respectively). The highly significant genotype $\times$ year interactions for measures of ELWL were reflected in genotypic correlations for measures of ELWL across the three years, around $40 \%$ of which were 
236 either non-significant or significant at only $P<0.05$ (Table S2). Despite the highly significant

237 genotype $\times$ year interaction for measures of ELWL, broad-sense heritability for ELWLW $\mathrm{C}_{0-3 \mathrm{~h}}$ was

238 high each year $\left(h^{2}=0.92,0.77,0.63\right.$ in $2007,2008,2009$, respectively). Although highly

239 significant experiment and experiment $\times$ line interaction effects were observed, to simplify

240 further description and analysis of results, phenotypic data for the three years were pooled

241 (except for traits measured only in experiment III).

242 The parents CS and SQ1 differed significantly for four leaf traits and all measures of 243 ELWL (Table 2), with SQ1 consistently having a greater ELWL than CS. SQ1 also had a 244 significantly smaller initial $\mathrm{FW}$, associated with significantly shorter leaves, leading to smaller 245 leaf areas.

246 Traits ranged amongst CSDH lines from 1.41-fold for leaf lamina thickness to 3.71-fold for 247 initial $\mathrm{FW} / \mathrm{cm}^{2}$ (Table 2). Transgressive segregation amongst DH lines was evident for many 248 traits, as max/min ratios amongst DH lines frequently exceeded parent ratios.

249 The large variation amongst CSDH lines in leaf size was reflected in ranges amongst 250 lines over 3-fold in initial $\mathrm{FW}$, DW, leaf area and initial leaf $\mathrm{FW} / \mathrm{cm}^{2}$. These led to similarly 251 large variation in water loss. However, the variation amongst lines in ELWL was $<2.0$ for $0-3 \mathrm{~h}$ 252 and 0-6h. Only for the period 3-6h was the range in ELWL amongst lines at least 2.5. ELWLW 3 253 6h showed the largest ranges amongst both lines (3.32-fold) and parents (2.63). Ranges for 254 ELWLF (FW basis) and ELWLD (DW basis) showed similar trends, with 0-3h, 3-6h and 0-6h 255 ranges of 1.94- 2.63- and 1.65-fold, respectively, for ELWLF and 2.25-, 2.86- and 2.14-fold, 256 respectively, for ELWLD. Measures of leaf thickness showed relatively little variation amongst 257 the lines ( $c a$. 1.5-fold).

258

259

260

Phenotypic associations amongst leaf traits

261

Leaf parameters associated with leaf size were highly significantly positively correlated with each other (Table 3). The only trait not correlated with leaf length was leaf lamina thickness. The 262 structural support provided by the midrib led to midrib thickness being significantly positively associated with leaf length, width, area, and lamina thickness. All these leaf size parameters were also highly significantly positively correlated with leaf initial FW, DW and initial $\mathrm{FW} / \mathrm{cm}^{2}$. Stomatal number/unit area was significantly negatively associated with leaf length, and weakly 266 positively associated with lamina thickness. 
All measures of ELWL were highly significantly positively correlated with each other for

268 0-3h and 0-6h, and most ELWL for 3-6h (Table 4). In general, correlations between ELWL $0-6 \mathrm{~h}$ 269 and other leaf parameters were very similar to those for $\mathrm{ELWL}_{0-3 \mathrm{~h}}$, but less significant, so $270 \mathrm{ELWL}_{0-6 \mathrm{~h}}$ is not discussed further. For 3-6h, only ELWLW was highly significantly positively 271 correlated between all measures of ELWL for 0-3h. Correlations of ELWLF, ELWLD and 272 ELWLA for 3-6h (except ELWLA EL-6h $_{\text {and }}$ ELWLA ${ }_{0-3 h}$ ) with other measures of ELWL for 0-3h 273 were either non-significant or only weakly significant.

274 Correlations between measures of ELWL and other leaf parameters showed clear patterns. 275 Thus, ELWLW $E_{0-3 \mathrm{~h}}$ and $\mathrm{ELWLF}_{0-3 \mathrm{~h}}$ were both highly significantly $(P<0.002)$ negatively 276 associated with leaf length, area and midrib thickness (larger leaves had lower ELWL) as well as 277 initial leaf FW and DW (Table 4). Correlations between both ELWLD and ELWLA and leaf size 278 parameters were either not significant or only weakly significant (negatively between ELWLD E- $^{-}$ $2793 \mathrm{~h}$ and leaf DW). For ELWLA, significant correlations $(P<0.05)$ occurred with leaf length and 280 area (negative for 0-3h) and lamina thickness (positive, 3-6h). Most correlations of ELWL $3-6 \mathrm{~h}$ 281 with measures of leaf size were non-significant. Only ELWLW 3 -6h was significantly correlated 282 (negatively) with leaf size parameters: leaf length, area, midrib thickness, initial FW and DW 283 (Table 4). ELWLF ${ }_{3-6 h}$ and ELWLD $3-6 \mathrm{~h}$ were not correlated with any leaf parameters.

Phenotypic associations of ELWL and other leaf traits with yield

Although yield was not measured in these excised-leaf experiments, yield/plant of the CSDH lines was measured in 52 other year $\times$ site $\times$ treatment trials. Amongst these, 12 experiments had control (rainfed or irrigated) and at least one effective drought treatment $(10-71 \%$ yield reduction). Mean yield/plant for these droughted treatments as well as the corresponding mean control yields (augmented with control [non-stressed] treatments from seven other trials) were used to calculate drought-induced yield effect for each $\mathrm{CSDH}$ line (expressed as droughted/control yield). Yield/plant for each line at site mean yields of 2 and $7 \mathrm{~g} / \mathrm{plant}$ was also calculated, as described in Materials and Methods. Associations between these five measures of yield and yield response to drought and measures of ELWL and non-ELWL leaf traits were analysed.

No measure of ELWL was significantly correlated with drought-induced yield reduction 297 (Table 5a). ELWL $0-3 \mathrm{~h}$ was more frequently significantly negatively correlated with measures of 
298 yield/plant than 0-6h data (Table S3), and 3-6h data were the least associated with measures of 299 yield/plant: only ELWLW $3-6 \mathrm{~h}$ and $\mathrm{ELWLF}_{3-6 \mathrm{~h}}$ were significantly correlated with droughted $300 \mathrm{yield} /$ plant and yield/plant at $7 \mathrm{~g}$ yield/plant. No ELWLD data were significantly correlated with 301 any measure of yield/plant for any time period.

302 Overall, measures of ELWL showing the most consistent significant correlations 303 (negatively) with measures of yield/plant were ELWLW E-3h $_{\text {and }}$ ELWLA $0-3 \mathrm{~h}$, with ELWLA $\mathrm{EL}_{0-3 \mathrm{~h}}$ 304 being correlated at $P<0.001$ with yield/plant at $7 \mathrm{~g} /$ plant (Table 5a). ELWLW $0-3 \mathrm{~h}$ and ELWLF $0-3 \mathrm{~h}$ 305 were more significantly negatively correlated with yield/plant under droughted than control 306 conditions. Thus, higher yield under drought was associated with lower ELWLW and ELWLF. 307 However, ELWLW ${ }_{0-3 h}$ and ELWLF $_{0-3 h}$ were equally significantly correlated $(P<0.005)$ with $308 \mathrm{yield} /$ plant estimated at site yields of 2 and $7 \mathrm{~g} / \mathrm{plant}$.

309 Correlations of non-ELWL leaf traits with yield/plant were positive. Thus, leaf length and 310 area, initial leaf FW and DW were usually significantly correlated with measures of yield/plant. 311 Leaf length was highly effective at predicting yield/plant under droughted conditions $312(P<0.0001)$, and leaf four area was highly effective at predicting yield/plant under favourable 313 conditions (site yield of $7 \mathrm{~g} /$ plant), $P<0.0001$ (Table 5b). Stomatal number $/ \mathrm{mm}^{2}$ was weakly 314 negatively correlated $(P<0.05)$ with droughted yield/plant and yield/plant under favourable 315 conditions (site yield of $7 \mathrm{~g} /$ plant).

316

317

Leaf 4 ELWL and length as selection criteria to improve yield

318 As ELWL has frequently been suggested to be a useful trait for selecting improved yield under 319 drought, ELWLW $0-3 \mathrm{~h}$ was compared with leaf length for their effectiveness at identifying higher320 yielding CSDH lines. For each of the two traits, the 94 lines were ranked according to either 321 increasing ELWL or decreasing leaf length and, for each water loss experiment, yields/plant for 322 the 10 lines with the lowest ELWLW $\mathrm{E}_{0-3 \mathrm{~h}}$ and 10 lines with the longest leaves were compared 323 with yields/plant for both the 10 lines at the opposite end of the rankings (highest ELWLW $0-3 \mathrm{~h}$ 324 and shortest leaves) and the remaining $84 \mathrm{CSDH}$ lines. Yields were compared for five groups: 325 mean yields from all 52 trials, control mean yields (19 lines), droughted mean yields (12 lines) 326 and yields at site mean yields of $7 \mathrm{~g} /$ plant and $2 \mathrm{~g} /$ plant (Table 6). 
327

328

329

330

331

332

333

334

335

336

337

338

339

340

341

342

343

344

345

346

347

348

349

350

351

352

353

354

355

356

357

Selecting the 10 most favourable and 10 least favourable CSDH lines resulted in highly significant yield differences for all 52 trials and the 19 control trials with both ELWLW E-3h $_{\text {and }}$ leaf length in each of the three experiments.

Comparing the 10 most favourable lines with the remaining 84 lines, yield advantages of selecting CSDH lines with the lowest ELWLW $\mathrm{E}_{0-3 \mathrm{~h}}$ were overall small for each yield group, averaging 3.1\% across the five yield groups for ELWLW $\mathrm{E}_{0-3 \mathrm{~h}}$, and significant only when meaned across the three experiments, for 52 trial mean yields, as well as the 19 control trials and a site mean yield of $2 \mathrm{~g} /$ plant (Table 6). Selecting for ELWLW ${ }_{0-3 \mathrm{~h}}$ gave no yield advantage with the 12 droughted trials.

Leaf length was, overall, a less effective selection criterion for increasing yield $/ \mathrm{plant}(0.7 \%$ over the five yield measures), and in 2007, selecting for longer leaves resulted in a significant reduction in mean yield/plant at a site mean yield of $7 \mathrm{~g} /$ plant. Nevertheless, leaf length was more effective at increasing yields in the droughted group $(P<0.05)$, giving a mean yield advantage under droughted conditions of 5.1\% (Table 6). Selecting for large leaf area similarly gave small and inconsistent yield benefits, averaging $2.3 \%$ higher yields over the five yield measures, compared with the 84 other lines (Table S4).

$\underline{\text { Genetic analyses }}$

To reduce the complexity of genetic analysis of ELWL and leaf traits, only 3-experiment mean data for the four ELWL traits ELWLW 0-3h $, \mathrm{ELWLA}_{0-3 \mathrm{~h}}, \mathrm{ELWLW}_{3-6 \mathrm{~h}}$ and ELWLA 3 -6h, as well as 3-experiment mean data for leaf length, width, area and experiment III data for midrib thickness are described in detail here. CIM was used with 3-expt-mean data, and QTL peaks coincident between SMA and CIM are identified in Table S1. About 20\% of QTLs classified as significant by SMA were also significant using CIM.

\section{Genetic analysis of ELWL}

Detailed genetic analysis using SMA focused on ELWLW and ELWLA for both 0-3h and 3-6h, using ratio means as described for Method 1 (Materials and Methods). Figure S2 demonstrates that SMA using Methods 1 and 2 gave very similar QTLs. ELWL $L_{0-3 \mathrm{~h}}$ peak maxima at 25 markers with the most significant MARs for $\mathrm{ELWL}_{0-3 \mathrm{~h}}$ 3-experiment-mean phenotypic data using Method 2 were highly significantly correlated $\left(\mathrm{r}_{23 \mathrm{df}}=0.997\right)$ with 3 -experiment-mean MARs at the same 
358 markers using Method 1. From this regression, a ratio of 1.0 for significance at $P=0.05$ using 359 Method 2 was equivalent to $c a .0 .7$ using Method 1.

360 Numbers of QTLs identified for ELWL traits using SMA varied from 20 to 30 (Table S1

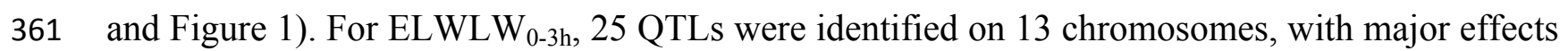
362 distal on 3AL (SQ1 high ELWLW allele) and 6BL, as well as 7DS (both CS high water loss 363 alleles). Thirty QTLs were identified for ELWLA E-3h , distributed on 17 chromosomes, of which 364 two major QTLs were located on 5A at the vrn-Al locus and 5BL, both with CS alleles 365 increasing ELWLA. ELWLW ${ }_{3-6 h}$ gave 24 QTL distributed on 14 chromosomes, with CS alleles 366 increasing ELWLA at major QTLs on 3DL, 5BL, 6BL and 7DS, and SQ1 contributing 367 increasing alleles at major QTLs on 3AL (two QTLs), 3B (three QTLs) and 6AL. ELWLA $3-6 \mathrm{~h}$ 368 gave 25 QTLs located on 14 chromosomes. SQ1 alleles increased ELWLA 3 -6h at two major 369 QTLs, on chromosomes 5AS and 6AL.

370 The four ELWL traits showed considerable similarities in MAR line traces and locations of 371 QTLs, with 11 QTLs coincident between ELWLW and ELWLA for a particular time period 372 (coincident arrowheads in Figure 1) and 23 QTLs coincident between time periods (triangles in 373 Figure 1). Ratios were significant and traces very similar distal on $3 \mathrm{AL}, 3 \mathrm{~B}$, distal on $3 \mathrm{DL}$, 4B, $3745 \mathrm{~B}, 6 \mathrm{~A}$, distal on $6 \mathrm{BL}$ and 7D.

375 Few QTLs were stably expressed each year, giving MARs $\geq 1(P \leq 0.05)$ in all experiments

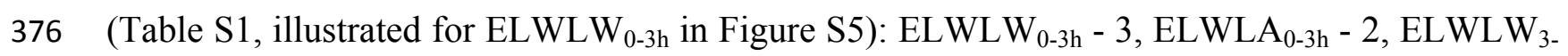
$3776 \mathrm{~h}-8$, ELWLA $_{3-6 \mathrm{~h}}$ - 1. Nevertheless, within experiments, genetic control of ELWL was 378 consistent across a range of time intervals. Thus, in 2007, leaf weights were also recorded after 379 water loss for $8 \mathrm{~h}$. Fourth-order polynomials were fitted to leaf weights sampled at 0, 3, 6 and $8 \mathrm{~h}$ 380 to calculate water loss after $1 \mathrm{~h}$, and ELWLW calculated for the intervals $0-1 \mathrm{~h}, 1-3 \mathrm{~h}, 3-6 \mathrm{~h}$ and 6$3818 \mathrm{~h}$. Eighteen genomic regions showed coincidence for all four time intervals (boxed in Figure 382 S6).

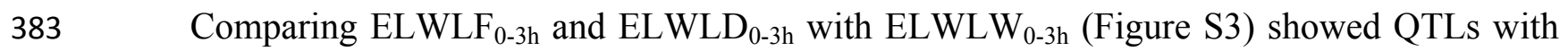
384 peak ratios $\geq 1.0$ (22 for $\mathrm{ELWLF}_{0-3 \mathrm{~h}}$ and 23 for $\mathrm{ELWLD}_{0-3 \mathrm{~h}}$ ) largely coincident with those for 385 ELWLW $_{0-3 h}$.

386

387

Genetic analysis of constitutive leaf traits 
388 SMA of leaf length, width, area and midrib thickness demonstrated MAR similarities between 389 leaf length and midrib thickness, and between leaf width and area (Figure 2). Numbers of QTLs 390 identified using SMA for leaf constitutive traits were similar to those for ELWL: length - 26, 391 width - 23, area - 26, thickness - 20 (Table S1). Leaf length QTLs were identified on 14 392 chromosomes, with the majority of QTLs having increasing alleles from CS. By far the largest 393 QTL for leaf length (CS alleles increasing) was on 4B, very close to the dwarfing gene Rht-B1. 394 Fifteen chromosomes had QTLs for leaf width, though the majority of QTLs were weak (MARs $395<1.0$ ). Major leaf width QTLs were present on chromosomes 3A, 4A, 6A and 6B, alleles 396 increasing leaf width from CS on $3 \mathrm{~A}$ and $4 \mathrm{~A}$, and from SQ1 on 6A and 6B. Leaf area QTLs were 397 distributed amongst 14 chromosomes, with major additive effects on 4A, 4B (CS alleles 398 increasing) and 5D (SQ1 alleles increasing). MARs more closely followed those for leaf width 399 400 401 402 403 than for leaf length (Figure 2). Twenty QTLs for midrib thickness were distributed amongst 13 chromosomes, with major QTLs located on chromosomes 1A, 2D, 3A, 4D (CS alleles increasing) and 5A and 6D (SQ1 alleles increasing).

\section{Coincidence of QTLs between ELWL and constitutive leaf traits}

As phenotypic correlations between ELWL and constitutive leaf traits were almost invariably negative (Table 4), the coincidence of QTLs for ELWL and constitutive leaf traits is compared (Figure 3a, b) with traces of MARs inverted for ELWLW ${ }_{0-3 \mathrm{~h}}, \mathrm{ELWLA}_{0-3 \mathrm{~h}}, \mathrm{ELWLW}_{3-6 \mathrm{~h}}$ and ELWLA $_{3-6 h}$. Although phenotypic correlations between leaf constitutive traits and measures of 408 ELWL were much more significant for ELWLW than for ELWLA, QTLs were coincident between all measures of ELWL and each of the four constitutive leaf traits: QTL coincidences with ELWLW ${ }_{0-3 h}$ were leaf length - 4, width - 2, area - 5, thickness - 4; ELWLA $_{0-3 h}$ with length 2, width - 4, area - 4, thickness - 3; ELWLW 3 -6h with length - 6, width - 3, area - 6, thickness - 3, and ELWLA 3 -6h with length - 2, width - 2, area - 4, thickness - 1. All four measures of ELWL were coincident with leaf trait QTLs distal on 1AL and near 3B centromere (Figure 3a). QTLs 414 specific for only ELWLW were coincident with leaf trait QTLs on 4B at the dwarfing gene Rht415 $B 1,5 \mathrm{DL}, 7 \mathrm{AL}$ and 7DS.

416 
418 Figure 4a, b shows MARs from SMA for five measures of yield (control, droughted, 419 droughted/control, yield at 7 and $2 \mathrm{t} \mathrm{ha}^{-1}$ ), together with mean MARs for all 52 yield trials, 420 ELWLW $_{0-3 \mathrm{~h}}$ and ELWLA $_{0-3 \mathrm{~h}}$. Yield QTLs combined using Method 1 from all trials were 421 consistently present with increasing alleles from CS on chromosomes 1D, 4A, 4B, 4D, 5A, 7A, $4227 \mathrm{~B}$, and from SQ1 on chromosomes 1D, 2B, 2D, 3D, 4B, 5D, 6B and 7A.

423 Many peak MARs were consistent across the four measures of yield/plant (arrowheads in 424 Figure 4) but differed from those for yield drought/control ratio (Figure 4). Major differences in 425 QTLs between the 19 control and 12 droughted yields were present on 16 chromosomes. 426 Increasing alleles were contributed by CS for control-specific QTLs on chromosomes 4D, 5D 427 and 7B, and by SQ1 on chromosomes 1A, 2B, 3B, 3D, 4B and 7A. Drought-specific QTLs were 428 present on 1A, 1D, 4B and 5A (increasing allele from CS), as well as 1D, 2A, 3D and 6B (SQ1 429 alleles increasing). QTLs with MARs $\geq 1$ for yield at a site yield of $7 \mathrm{t} \mathrm{ha}^{-1}$, were located on 430 chromosomes 1A (CS alleles increasing) and 2B, 3D, 4D and 7A (SQ1 alleles increasing). For 431 yield at a site yield of $2 \mathrm{t} \mathrm{ha}^{-1}$, QTLs were found on chromosomes 1B, 2B, 4A and 7A (CS alleles 432 increasing), as well as 2D, 3B and 6A (SQ1 alleles increasing).

433

Yield response to drought (drought/control) showed highly significant $(P<0.001)$ QTLs on chromosomes 1D and 5D (increasing alleles from CS and SQ1, respectively), with other major QTLs $(P<0.01)$ on chromosomes 1A, 3A, 4B and 7A (increasing alleles from CS), and 2A and 6B (increasing alleles from SQ1).

\section{Coincidence of QTLs between yield, ELWL and constitutive leaf traits}

Peak MARs for four ELWL and four constitutive leaf traits (QTLs listed in Table S1) were used to test the likelihood of these traits determining one or other of the measures of yield. Thus, for each ELWL and leaf trait peak MAR (Table S1), the MAR was determined for each of the five measures of yield at either that marker or an adjacent marker if a yield MAR peak was within 10 $\mathrm{cM}$ and correlation coefficients were calculated for regressions of these yield peak MARs on peak MARs for the eight ELWL and leaf constitutive traits (Table 7).

As for phenotypic associations with yield, significant correlations of yield with ELWL traits were predominantly negative, and those with leaf constitutive traits predominantly positive. Significant correlations with leaf constitutive traits were more frequent than those with ELWL 448 traits, and generally stronger. Using MARs, ELWLA 3 -6h and leaf midrib thickness were not 
449 correlated with any measure of yield. Leaf 4 length was the trait most consistently highly 450 correlated with measures of yield, except yield drought response (drought/control), illustrated for 451 droughted yields in Figure S4a.

452 In contrast, ELWLW E-3h and ELWLA $_{0-3 \mathrm{~h}}$ were significantly negatively correlated with

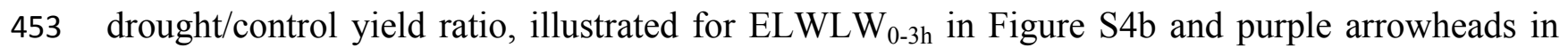
454 Figure 4. Thus low water loss was associated with a relatively high yield under drought.

455

\section{Discussion}

\section{The physiological control of ELWL and its genetic variation}

458 We selected leaf 4 from glasshouse-grown plants for our genetic analysis of ELWL, as the 459 mapping population varies considerably in phenology (Quarrie et al. 2005), with days to flag leaf emergence varying over two weeks (Table S5). Others have also studied leaf water loss in young plants (Golestani Araghi and Assad 1998, Rampino et al. 2006), though Clarke (1983) found a genotype $\times$ environment interaction comparing glasshouse and field-grown plants sampled near anthesis.

ELWLW was usually highly negatively correlated with aspects of leaf size: leaf DW, leaf area, leaf length, as well as midrib thickness (Table 4), implying that a longer path length for water to reach the epidermis slowed rate of water loss from the leaf surface. Significant negative associations between rate of water loss and leaf area have been found by others in both sorghum (Ali et al. 2011) and wheat flag leaves (Sayed and Bedawy 2016). Although variation in ELWLA could also reflect variation in leaf thickness, no significant relationship was found between ELWLA and leaf midrib thickness. Thus, distance from vascular bundles to the epidermis per se was unlikely to be a factor determining rate of water loss. The highly significant negative correlation between midrib thickness and ELWLW $0_{0-3 \mathrm{~h}}$ likely reflected the greater structural requirement of a thicker midrib as leaf length increased.

Stomatal number per unit area was not a factor in determining genotypic variation in ELWL amongst the CSDH lines (Table 4), though Wang and Clarke (1993) found a highly significant positive correlation between rate of water loss up to $2 \mathrm{~h}$ from excision and stomatal

477 frequency amongst 12 hexaploid wheats. Furthermore, genotypic variation in the rate of water 478 loss was unlikely to indicate genotypic variation in stomatal aperture as correlations for a given measure of ELWL between 0-3h and 3-6h (Table 4) were all significant, and stomata would be 
480 expected to have closed within a few minutes of leaf detachment as leaves lost turgor. 481 Nevertheless, genotypic differences in non-stomatal water loss due to variation in cuticular 482 thickness or composition, already reported for wheat (e.g. Clarke and Richards 1988, Jäger et al. 483 2014, Bi et al. 2016, 2017a), could have contributed to the variation amongst CSDH lines in 484 ELWL. It was not possible with the hand sections of experiment III to assess cuticle thickness.

485

486

The genetic control of ELWL and candidate genes

487 As additive effects using SMA varied up to 1.7-fold amongst experiments, additive ratios 488 [Method 1] were used to compare between experiments and traits. Our QTL analyses (Table S1) 489 demonstrated a broad genetic control of ELWL with QTLs distributed across several 490 chromosomes, with increasing alleles from both parents, though few QTLs were stably expressed 491 every year. MAR traces of ELWLW for different time intervals in 2007 (Figure S6) implied the 492 same genetic control of water loss for each time interval. Figure 1 confirms the extensive coincidence between 0-3h and 3-6h QTLs for both ELWLW and ELWLA. Therefore, it is probable that genetic variation in water loss was determined largely by non-stomatal characteristics. Although no cuticular traits were measured in our detached leaf experiments, visual assessment of CSDH line leaf waxiness at the tillering phase in the field in 2004 scored from 1 (very little visible wax) to 3 (thick greyish wax) showed QTLs coincident with those for ELWLW $_{0-3 \mathrm{~h}}$ on 5BL and 5DL (QELWLW $W_{0-3 .} . c s d h-5 B .2$ and $\left.Q E L W L W_{0-3 .} . c s d h-5 D .1\right)$ (Table S6).

Yang et al. (2009) and Mei (2012) have reported preliminary information on the genetic 500 control of ELWL in wheat. Yang et al. (2009) identified QTLs on chromosomes 1D, 4A, 6B and 501 6D, with those on 6B (near locus Xgwm193) and 6D (near locus Xbarc173) being coincident

502

503

504

505

506

507

508

509

510 with weak ELWL QTLs in our mapping population. Mei (2012) reported an additional QTL for ELWL on chromosome 2A where we also had a weak QTL effect.

Two likely classes of candidate gene for regulating leaf water loss would be those regulating water flow to the epidermis and those regulating its evaporation from the leaf surface through the cuticle. Aquaporins are water channel proteins belonging to the Major Intrinsic Protein superfamily of integral membrane proteins which specifically facilitate the passive flow of water molecules across cellular membranes (Maurel, 1997). Forrest and Bhave (2010) assigned several aquaporin genes to wheat chromosome bins. Plasma membrane aquaporin genes PIP1;1, PIP1;2, PIP2;2 and PIP2;1 were located in bins corresponding to ELWL QTLs on 2BS, 
511 6AL and 7AS, respectively (Table S1). Tonoplast membrane aquaporins TIP1;2 and TIP2;1 were

512 in bins corresponding to ELWL QTLs on 4BS and 6BL, respectively. An aquaporin gene listed 513 in the GrainGenes wEST SQL bin-mapped markers database (http://wheat.pw.usda.gov/cgi514 bin/westsq1/map_locus.cgi; downloaded June 2006 as an Excel ${ }^{\mathrm{MS}}$ file and searched for

515 "aquaporin"), BE403397, was located on bins C-2AL1-0.85, 6AL4-0.55-0.90 and 6BL5-0.40516 1.00, each coincident with bins for ELWL QTLs (Table S1).

517 A recent publication by Bi et al. (2017b), reported the location of genes for several 518 transcription factors regulating cuticle biosynthesis genes on the group 5 long arms, 6BL and 519 6DL. Two more genes with high sequence identity were found on 4A and 4D. QTLs for 520 measures of ELWL were present on 5AL, 5BL, 5DL and 6BL. Only weak effects on ELWL 521 were found on 4A and 4D. The well-characterised leaf waxiness genes $W 1$ and $I w 1$ (Wu et al. 522 2013, Hen-Avivi et al. 2016) map distally on 2BS, where a QTL for ELWLA 3 -6h was located 523 (Table S1). Thus, some of the genes influencing ELWL may be associated with the regulation of 524 water transport through aquaporins and genes for wax biosynthesis.

525

526

ELWL as a trait for improving drought tolerance

527 Many authors have proposed excised-leaf water loss (or water retention), measured on the basis

528 of either leaf water, fresh weight or dry weight, as a selection criterion to help improve drought 529 tolerance (e.g. Dedio, 1975; Clarke \& McCaig, 1982b; Yang et al., 1991; Dhanda \& Sethi, 1998; 530 David, 2010). Indeed, significant positive relationships between excised-leaf water retention and 531 yield have been found in studies on wheat genotypes under drought conditions (Clarke et al., 532 1989; Petcu, 2005; Geravandi et al., 2011), though not always (Clarke et al., 1989; Dabiry et al., 533 2015).

$534 \quad$ Clarke and Townley-Smith (1986) and Clarke (1989) demonstrated that selection for both 535 high and low excised-leaf water retention in durum wheat crosses gave yield advantages for 536 selections with low ELWL, but only under drought conditions. We therefore tested the efficacy 537 of $\mathrm{ELWL}_{0-3 \mathrm{~h}}$ as a selection criterion for yield in the CSDH population and compared this with 538 leaf 4 length, a much simpler trait to measure and one very similar to ELWL in its phenotypic 539 correlations with yield under both control and droughted conditions (Table 5a,b). Although we 540 demonstrated a yield advantage for the $10 \mathrm{CSDH}$ lines with both the lowest $\mathrm{ELWL}_{0-3 \mathrm{~h}}$ and 541 longest leaves compared with the 10 lines at the opposite end of the trait rankings, as a breeding 
542 criterion, the advantage of selecting for low ELWL $\mathrm{EL}_{0-3 \mathrm{~h}}$ was much less apparent (Table 6), with an

543 overall yield advantage of only around 3\% compared with the remaining lines in the population, 544 with no clear additional benefit under droughted conditions. Therefore, as a selection criterion,

545 ELWL $_{0-3 \mathrm{~h}}$ would probably be no more effective than leaf 4 length in improving wheat yields.

546

547

548

549

550

551

552

553

554

555

556

557

558

559

560

561

562

563

564

565

566

567

568

569

570

571

\section{Conclusions}

To conclude, our genetic analysis of ELWL showed many regions of the wheat genome to contribute to variation in water loss, with few dominant and stably expressed QTLs. Only 13\% of QTLs for ELWL traits reached significance in every year (Table S1). Nevertheless, ELWLW - $_{\text {- }}$ $3 \mathrm{~h}$ and ELWLA $_{0-3 \mathrm{~h}}$ were significantly negatively correlated with grain yield, but irrespective of water status. As a yield selection criterion, ELWLW ${ }_{0-3 \mathrm{~h}}$ and leaf length were equally effective.

\section{References:}

Ali MA, Abbas A, Awan SI, Jabran K, Gardezi SDA. 2011. Correlated response of various morpho-physiological characters with grain yield in sorghum landraces at different growth phases. Journal of Animal and Plant Sciences 21:671-679.

Bayles BB, Taylor JW, Bartel AT. 1937. Rate of water loss in wheat varieties and resistance to artificial drought. Journal of American Society of Agronomy 29:40 52.

Bi H, Luang S, Li Y, Bazanova N, Morran S, Song Z, Perera AM, Hrmova M, Borisjuk N, Lopato S. 2016. Identification and characterization of wheat drought-responsive MYB transcription factors involved in the regulation of cuticle biosynthesis Journal of Experimental Botany 67:5363-5380, https://doi.org/10.1093/jxb/erw298.

Bi H, Kovalchuk N, Langridge P, Tricker PJ, Lopato S, Borisjuk N. 2017a. The impact of drought on wheat leaf cuticle properties. BMC Plant Biology 17:85 DOI 10.1186/s12870017-1033-3.

Bi H, Luang S, Li Y, Bazanova N, Borisjuk N, Hrmova M, Sergiy Lopato S. 2017b. Wheat drought-responsive WXPL transcription factors regulate cuticle biosynthesis genes. Plant Molecular Biology (online) DOI 10.1007/s11103-017-0585-9. 
572 Chandra D, Islam MA. 2003. Genetic variation and heritability of excised-leaf water loss and

573 its relationship with yield and yield components of $\mathrm{F}_{5}$ bulks in five wheat crosses. Journal of 574 Biological Sciences (ISSN 1727-3048) 3:1032-1039.

575 Clarke JM. 1983. Differential excised-leaf water retention capabilities of Triticum cultivars 576 grown in field and controlled environments. Canadian Journal of Plant Science 63:539-541.

577 Clarke JM. 1987. Use of physiological and morphological traits in breeding programmes to 578 improve drought resistance of cereals. In: Drought Tolerance in Winter Cereals (Eds. J.P. 579 Srivastava, E. Porceddu, E. Acevedo, S. Varima. John Wiley \& Sons Ltd. Pp 171-188.

580 Clarke JM, McCaig TN. 1982a. Excised-leaf water retention capability as an indicator of 581 drought resistance of Triticum genotypes. Canadian Journal of Plant Science 62:571-578.

582 Clarke JM, McCaig TN. 1982b. Evaluation of techniques for screening for drought resistance 583 in wheat. Crop Science 22:503-506.

Clarke JM, Townley-Smith TF. 1986. Heritability and relationship of excised leaf water retention in durum wheat. Crop Science 26:289-292.

Clarke JM, Richards RA. 1988. The effects of glaucousness, epicuticular wax, leaf age, plant height, and growth environment on water loss rates of excised wheat leaves. Canadian Journal of Plant Science 68:975-82.

Clarke JM, Romagosa I, Jana S, Srivastava JP, McCaig TN. 1989. Relationship of excisedleaf water loss rate and yield of durum wheat in diverse environments. Canadian Journal of Plant Science 69:1075-1081.

Czyczyło-Mysza 2013. Identification of quantitative trait loci (QTL) controlling photochemical and photosynthetic activity and yield of wheat plants under drought conditions using a mapping population of CSDH lines. Monograph 16. Wyd. IFR PAN, Kraków, ISBN 978-8386878-31-4 (in Polish).

Czyczyło-Mysza I, Tyrka M, Marcinska I, Skrzypek E, Karbarz M, Dziurka M, Hura T, Dziurka K, Quarrie SA. 2013. Quantitative trait loci for leaf chlorophyll fluorescence parameters, chlorophyll and carotenoid contents in relation to biomass and yield in bread wheat and their chromosome deletion bin assignments. Molecular Breeding 32:189-210.

Dabiry S, Esmaeili MA, Haghparast R, Ghajarsepanlo M. 2015. Drought tolerance of advanced bread wheat genotypes based on different drought tolerance criteria. Biological Forum - An International Journal 7:230-241. 
603 David M. 2010. Water loss from excised leaves in a collection of triticum aestivum and triticum 604 durum cultivars. Romanian Agricultural Research 27:27-34.

605 Dedio W. 1975. Water relations in wheat leaves as screening tests for drought resistance. 606 Canadian Journal of Plant Science 55:369-378.

607 Dhanda SS, Sethi GS. 1998. Inheritance of excised-leaf water loss and relative water content in 608 bread wheat. Euphytica 104:39-47.

609 Dodig D, Quarrie SA, Stanković S, Milijić S, Denčić S. 2002. Characterising wheat genetic 610 resources for responses to drought stress. In: Proceedings of the ICID international 611 conference on 'drought mitigation and prevention of land desertification', 21-25 April 2002, 612 Bled, Slovenia. 38doc.pdf, CD edition (available for download at 613 https://www.researchgate.net/publication/267384415_Characterising_wheat_genetic_resourc 614 es_for_responses_to_drought_stress)

615 Dudley SA. 1996. Differing selection on plant physiological traits in response to environmental 616 water availability: A test of adaptive hypotheses. Evolution 50:92-102.

617 Forrest KL, Bhave M. 2010. Physical mapping of wheat aquaporin genes. Theoretical and 618 Applied Genetics 120:863-873

619 Foulkes MJ, Sylvester-Bradley R, Weightman R, Snape J. 2007. Identifying physiological 620 traits associated with improved drought resistance in winter wheat. Field Crops Research 621 103:11-24.

622

Geravandi M, Farshadfar E, Kahrizi D. 2011. Evaluation of some physiological traits as 623 indicators of drought tolerance in bread wheat genotypes. Russian Journal of Plant Physiology, Vol. 58, No. 1, pp. 69-75. doi: 10.1134/S1021443711010067.

625

626

627

Golestani Araghi S, M.T. Assad MT. 1998. Evaluation of four screening techniques for drought resistance and their relationship to yield reduction ratio in wheat. Euphytica 103:293-299, 1998.

Habash DZ, Bernard S, Schondelmaier J, Weyen J, Quarrie S. 2007. The genetics of nitrogen use in hexaploid wheat: $\mathrm{N}$ utilisation, development and yield. Theoretical and Applied Genetics 114:403-419.

631

Haley SD, Quick JS, Morgan JA. 1993. Excised-leaf water status evaluation and associations 632 in field-grown winter wheat. Canadian Journal of Plant Science 73:55-63. 
633

634

635

636

637

638

639

640

641

642

643

644

645

646

647

648

649

650

651

652

653

654

655

656

657

658

659

660

661

662

663

Hen-Avivi S, Savin O, Racovita RC, Lee W-S, Adamski NM, Malitsky S, Almekias-Siegl E, Levy M, Vautrin S, Bergès H, Friedlander G, Kartvelishvily E, Ben-Zvi G, Alkan N, Uauy C, Kanyuka K, Jetter R, Distelfeld A, Aharon A. 2016. A metabolic gene cluster in the wheat $W 1$ and the barley Cer-cqu loci determines $\beta$-diketone biosynthesis and glaucousness. The Plant Cell 28:1440-1460

Jäger K, Fábián A, Eitel G, Szabó L, Deák C, Barnabás B, Papp I. 2014. A morphophysiological approach differentiates bread wheat cultivars of contrasting tolerance under cyclic water stress. Journal of Plant Physiology 171:1256-1266, doi:10.1016/j.jplph.2014.04.013.

Kirkham MB, Smith EL, Dhanasobhon C, Drake TI. 1980. Resistance to water loss of winter wheat flag leaves. Cereal Research Communications 8:393-399.

Mangin B, Goffinet B. 1997. Comparison of several confidence intervals for QTL location. Heredity 7:345-353.

Maurel C .1997. Aquaporins and water permeability of plant membranes. Annual Review of Plant Physiology and Plant Molecular Biology 48:399-429.

Mei A. 2012. Construction of molecular genetic linkage map and QTL mapping analysis of flag leaf traits associated with drought tolerance in wheat (Triticum aestivum L.). MSc thesis, Gansu Agricultural University, China.

Monneveux P, Jing R, Misra SC. 2012. Phenotyping for drought adaptation in wheat using physiological traits. Frontiers in Physiology volume 3, Article 429 pp 1-12.

Petcu E. 2005. The effect of water stress on cuticular transpiration and relationships with winter wheat yield. Romanian Agricultural Research 22:15-19.

Quarrie SA, Jones HG. 1977. Effects of abscisic acid and water stress on development and morphology of wheat. Journal of Experimental Botany 28:192-203.

Quarrie SA, Pekić Quarrie S, Radošević R, Rančić D, Kaminska A, Barnes JD, Leverington M, Ceoloni C, Dodig D. 2006. Dissecting a wheat QTL for yield present in a range of environments: from the QTL to candidate genes. Journal of Experimental Botany 57:2627-2637.

Quarrie SA, Steed A, Calestani C, Semikhodskii A, Lebreton C, Chinoy C, Steele N, Pljevljakusic D, Waterman W, Weyen J, Schondelmaier J, Habash DZ, Farmer P, Saker L, Clarkson DT, Abugalieva A, Yessimbekova M, Turuspekov Y, Abugalieva S, 
664

665

666

667

668

669

670

671

672

673

674

675

676

677

678

679

680

681

682

683

684

685

686

687

688

689

690

691

692

693

694

Tuberosa R, Sanguineti M-C, Hollington PA, Aragues R, Royo A, Dodig D. 2005. A high density genetic map of hexaploid wheat (Triticum aestivum L.) from the cross Chinese Spring x SQ1 and its use to compare QTLs for grain yield across a range of environments. Theoretical and Applied Genetics 110:865-880.

Rampino P, Pataleo S, Garardi C, Mita G, Perrotta C. 2006. Drought stress response in wheat: physiological and molecular analysis of resistant and sensitive genotypes. Plant, Cell and Environment 29:2143-2152

Ravaglia S. 2005. Incremento della stabilità qualitativa e produttiva del frumento tenero attraverso strategie ecocompatibili di miglioramento varietale. In: Assemblea Ordinaria dei Soci. Centro Ricerche Produzioni Vegetali - Società cooperative 25:244-246.

Reynolds MP, Saint Pierre C, Vargas M. 2007. Evaluating potential genetic gains in wheat associated with stress-adaptive trait expression in elite genetic resources under drought and heat stress. Crop Science 47(S3) S172-S189. doi: 10.2135/cropsci2007.10.0022IPBS

Salim MH, Todd GW, Stutte CA. 1969. Evaluation of techniques for measuring drought avoidance in cereal seedlings. Agronomy Journal 61:182-185.

Sayed MAA, Bedawy IMA. 2016. Heterosis and inheritance of some physiological criteria imparting drought tolerance of grain sorghum in the irrigated and water-limited environments. Egyptian Journal of Agronomy 38:293-318.

Shapiro SS, Wilk MB. 1965. An analysis of variance test for normality (complete samples). Biometrika 52:591-611.

Wang S, Basten CJ, Zeng Z-B. 2011. Windows QTL Cartographer 2.5. Department of Statistics, North Carolina State University, Raleigh, NC

Wang H, Clarke JM. 1993. Relationship of excised-leaf water loss and stomatal frequency in wheat. Canadian Journal of Plant Science 73:93-99.

Winter SR, Music TS, Porter KB. 1988. Evaluation of screening techniques for breeding drought resistant winter wheat. Crop Science 28:512-516.

Wu H, Qin J, Han J, Zhao X, Ouyang S, Liang Y, Zhang D, Wang Z, Wu Q, Xie J, Cui Y, Peng H, Sun Q, Liu Z. 2013. Comparative high-resolution mapping of the wax inhibitors Iw1 and Iw2 in hexaploid wheat. PLoS ONE 8(12): e84691. doi:10.1371/journal.pone.0084691.

Yang RC, Jana S, Clarke JM. 1991. Phenotypic diversity and associations of some potentially 
695 drought-responsive characters in durum wheat. Canadian Journal of Plant Science 31:14846961491.

697 Yang DL, Jing R.L, Li W, Chang XP. 2009. Genetic dissection of QTL for RWC, RWL and 698 CTD associated with drought tolerance in wheat. Proceedings of Interdrought III. L 5.08 $699 \quad$ (abstract) 


\section{Table $\mathbf{1}$ (on next page)}

A) Results of two-way analysis of variance for traits measured in experiments I-III. B) Analysis of variance for traits measured only in experiment III (2009). 


\begin{tabular}{|c|c|c|c|c|c|c|c|c|c|c|c|}
\hline \multirow[b]{3}{*}{ Trait } & \multicolumn{8}{|c|}{ Source of variation } & \multirow{2}{*}{\multicolumn{3}{|c|}{ F-ratio for: }} \\
\hline & \multicolumn{2}{|c|}{ CSDH line } & \multicolumn{2}{|r|}{ Year } & \multicolumn{2}{|c|}{ CSDH line $\times$ Year } & \multicolumn{2}{|r|}{ Error } & & & \\
\hline & d.f. & m.s. & d.f. & m.s. & d.f. & m.s. & d.f. & m.s. & $\begin{array}{c}\text { CSDH } \\
\text { line }\end{array}$ & Year & $\begin{array}{c}\text { CSDH } \\
\text { line } \times \\
\text { Year }\end{array}$ \\
\hline $0-3 \mathrm{~h}$ water loss & 93 & 0.007914 & 2 & 0.2526 & 186 & 0.002145 & 554 & 0.0008804 & 8.99 & 286.9 & 2.44 \\
\hline $3-6 h$ water loss & 93 & 0.00244 & 2 & 0.08703 & 186 & 0.0007265 & 555 & 0.0003237 & 7.54 & 268.9 & 2.24 \\
\hline $0-6 \mathrm{~h}$ water loss & 93 & 0.01612 & 2 & 0.5511 & 186 & 0.003362 & 554 & 0.001485 & 10.85 & 371.0 & 2.26 \\
\hline Leaf length & 93 & 93.39 & 2 & 1050.0 & 186 & 11.37 & 556 & 4.495 & 20.77 & 233.7 & 2.53 \\
\hline Leaf width & 93 & 0.05378 & 2 & 2.653 & 186 & 0.01897 & 556 & 0.006906 & 7.79 & 384.1 & 2.75 \\
\hline Leaf area & 93 & 70.51 & 2 & 2163.7 & 186 & 16.17 & 555 & 6.245 & 11.29 & 346.5 & 2.59 \\
\hline Initial FW (0h) & 93 & 0.03148 & 2 & 1.463 & 186 & 0.005734 & 554 & 0.002547 & 12.36 & 574.5 & 2.25 \\
\hline Leaf DW (48h) & 93 & 0.000451 & 2 & 0.03479 & 186 & 0.0001143 & 554 & 0.00005021 & 8.98 & 692.9 & 2.28 \\
\hline Initial leaf $\mathrm{FW} / \mathrm{cm}^{2}$ & 93 & 21.283 & 2 & 997.756 & 186 & 8.039 & 554 & 4.170 & 5.10 & 239.25 & 1.93 \\
\hline ELWLW (0-3h) & 93 & 455.9 & 2 & 7752.5 & 186 & 247.0 & 553 & 59.44 & 7.67 & 130.4 & 4.16 \\
\hline ELWLA (0-3h) & 93 & 15.32 & 2 & 396.4 & 186 & 8.172 & 555 & 3.032 & 5.05 & 130.8 & 2.70 \\
\hline ELWLW (3-6h) & 93 & 2280.0 & 2 & 2460.2 & 186 & 602.2 & 547 & 166.6 & 13.69 & 14.8 & 3.61 \\
\hline ELWLA (3-6h) & 93 & 6.086 & 2 & 81.70 & 186 & 2.606 & 555 & 0.9906 & 6.14 & 82.5 & 2.63 \\
\hline ELWLW (0-6h) & 93 & 771.1 & 2 & 3157.0 & 186 & 255.8 & 553 & 59.03 & 13.06 & 53.5 & 4.33 \\
\hline ELWLA (0-6h) & 93 & 30.56 & 2 & 475.8 & 186 & 10.61 & 555 & 3.840 & 7.96 & 123.9 & 2.76 \\
\hline
\end{tabular}

All main effects for both factors and for interaction effects for all traits were significant at the $P<0.001$ level

2

$3 \mathbf{B}$

\begin{tabular}{lccccccc}
\hline \multicolumn{7}{c}{ Source of variation } \\
\multirow{2}{*}{ Trait } & \multicolumn{2}{c}{ CSDH line } & \multicolumn{2}{c}{ Error } & \multirow{2}{*}{ F-ratio } & \multirow{2}{*}{ P-value } \\
\hline Leaf lamina thickness & 93 & 830.8 & 180 & 204.5 & 4.06 & $<0.001$
\end{tabular}


$\begin{array}{lcccccc}\text { Leaf midrib thickness } & 93 & 12416 & 178 & 6233 & 1.99 & <0.001 \\ \text { Stomata per field of view } & 93 & 43.24 & 180 & 17.34 & 2.49 & <0.001\end{array}$ 


\section{Table 2 (on next page)}

Phenotypicvariation amongst CSDH lines and their parents Chinese Spring and SQ1 for traitdata meaned across experiments I, II and III. SD for the parent traitsindicates experimental variation. Traits shown in italics were measured only inexperiment III (2

SD for the parent traits indicates experimental variation. Traits shown in italics were measured only in experiment III (2009).

Significance levels: $* P \leq 0.05, * * P \leq 0.01$ indicate significance of differences between parents using a paired-sample $t$-test for traits measured in all three experiments. No parental means were significantly different for traits measured only in Experiment III.

₹ Calculated on the basis of leaf water content after $3 \mathrm{~h}$. 


\begin{tabular}{|c|c|c|c|c|c|c|c|}
\hline \multirow[t]{2}{*}{ Trait } & \multicolumn{3}{|c|}{ Parents (mean \pm SD) } & \multicolumn{4}{|c|}{ CSDH lines } \\
\hline & CS & SQ1 & ratio SQ1/CS & mean of 94 & $\min$ & $\max$ & $\max / \min$ \\
\hline 0-3h water loss $(\mathrm{g})$ & $0.145( \pm 0.028)$ & $0.133( \pm 0.041)$ & 0.92 & 0.147 & 0.078 & 0.245 & 3.13 \\
\hline 3-6h water loss (g) & $0.0506( \pm 0.0170)$ & $0.0591( \pm 0.0292)$ & 1.17 & 0.0604 & 0.0293 & 0.1018 & 3.47 \\
\hline 0-6h water loss (g) & $0.196( \pm 0.045)$ & $0.192( \pm 0.070)$ & 0.98 & 0.208 & 0.107 & 0.301 & 2.80 \\
\hline Leaf length $(\mathrm{cm})$ & $34.18( \pm 1.47)$ & $24.88( \pm 4.76)^{*}$ & 0.73 & 29.48 & 20.16 & 40.01 & 1.99 \\
\hline Leaf width $(\mathrm{cm})$ & $0.622( \pm 0.084)$ & $0.644( \pm 0.126)$ & 1.07 & 0.665 & 0.489 & 0.889 & 1.82 \\
\hline Leaf area $\left(\mathrm{cm}^{2}\right)$ & $16.70( \pm 2.99)$ & $12.63( \pm 4.04)^{*}$ & 0.76 & 15.47 & 7.68 & 24.07 & 3.13 \\
\hline $\begin{array}{l}\text { Leaf lamina } \\
\text { thickness }{ }^{\S}(\mu \mathrm{m})\end{array}$ & $247.4( \pm 7.2)$ & $262.0( \pm 13.4)$ & 1.06 & 248.9 & 206.4 & 290.1 & 1.41 \\
\hline $\begin{array}{l}\text { Leaf midrib thickness } \\
(\mu \mathrm{m})\end{array}$ & $668.4( \pm 62.3)$ & $589.5( \pm 14.8)$ & 0.88 & 672.5 & 524.9 & 805.0 & 1.53 \\
\hline Initial FW (0 h) (g) & $0.331( \pm 0.067)$ & $0.237( \pm 0.092)^{*}$ & 0.72 & 0.299 & 0.131 & 0.459 & 3.50 \\
\hline Leaf DW (g) & $0.042( \pm 0.014)$ & $0.038( \pm 0.017)$ & 0.90 & 0.039 & 0.018 & 0.058 & 3.18 \\
\hline Initial leaf FW $(\mathrm{mg}) / \mathrm{cm}^{2}$ & $19.77( \pm 0.59)$ & $18.45( \pm 2.47)$ & 1.07 & 19.26 & 12.42 & 46.08 & 3.71 \\
\hline Stomata per field of view & $25.00( \pm 5.02)$ & $26.33( \pm 4.80)$ & 1.05 & 25.45 & 15.25 & 35.50 & 2.33 \\
\hline ELWLW (0-3h) & $50.22( \pm 4.94)$ & $68.35( \pm 5.93)^{*}$ & 1.36 & 58.07 & 44.54 & 85.09 & 1.91 \\
\hline ELWLA (0-3h) & $9.16( \pm 1.17)$ & $10.95( \pm 0.73)^{*}$ & 1.20 & 10.10 & 7.53 & 14.84 & 1.97 \\
\hline ELWLW (3-6h) & $34.84( \pm 9.20)$ & $91.57( \pm 10.02)^{*}$ & 2.63 & 60.03 & 27.80 & 92.40 & 3.32 \\
\hline ELWLA (3-6h) & $3.11( \pm 0.70)$ & $4.66( \pm 0.98)^{*}$ & 1.50 & 4.04 & 2.42 & 6.05 & 2.50 \\
\hline ELWLW (0-6h) & $67.29( \pm 6.90)$ & $97.02( \pm 3.42)^{*}$ & 1.44 & 81.17 & 61.73 & 99.12 & 1.61 \\
\hline ELWLA $(0-6 \mathrm{~h})$ & $10.40( \pm 4.37)$ & $12.96( \pm 4.52)^{* *}$ & 1.25 & 11.86 & 8.76 & 16.09 & 1.84 \\
\hline
\end{tabular}




\section{Table 3 (on next page)}

Correlation coefficients for associations amongst leaf traits.

Correlation coefficients for associations amongst leaf traits, using data for each CSDH line and trait meaned across the three experiments, except leaf lamina, midrib thickness and stomatal number/unit area (experiment III), for which experiment III data only were used for all correlations. Significance level indicated by intensity of cell shading - green: positive, and red: negative correlations. 
1

\begin{tabular}{|c|c|c|c|c|c|c|c|c|}
\hline & $\begin{array}{l}\text { Leaf } \\
\text { length }\end{array}$ & $\begin{array}{l}\text { Leaf } \\
\text { width }\end{array}$ & $\begin{array}{l}\text { Leaf } \\
\text { area }\end{array}$ & $\begin{array}{c}\text { Lamina } \\
\text { thickness }\end{array}$ & $\begin{array}{l}\text { Midrib } \\
\text { thick. }\end{array}$ & $\begin{array}{l}\text { Initial } \\
\text { FW }\end{array}$ & $\begin{array}{l}\text { Leaf } \\
\text { DW }\end{array}$ & $\begin{array}{c}\text { Initial } \\
\text { FW/cm² }\end{array}$ \\
\hline Leaf width & 0.326 & & & & & & & \\
\hline Leaf area & 0.784 & 0.834 & & & & & & \\
\hline Leaf lamina thickness & 0.197 & 0.611 & 0.515 & & & & & \\
\hline Leaf midrib thickness & 0.372 & 0.453 & 0.506 & 0.588 & & & & \\
\hline Leaf initial FW (0h) & 0.780 & 0.734 & 0.929 & 0.584 & 0.585 & & & \\
\hline Leaf DW & 0.697 & 0.805 & 0.927 & 0.602 & 0.566 & 0.914 & & \\
\hline Initial leaf $\mathrm{FW} / \mathrm{cm}^{2}$ & 0.781 & 0.715 & 0.917 & 0.574 & 0.580 & 0.999 & 0.891 & \\
\hline \multirow[t]{2}{*}{ Stomatal number/unit area } & -0.352 & 0.167 & -0.090 & 0.203 & -0.202 & -0.131 & -0.007 & -0.146 \\
\hline & $P<0.05$ & $\mathrm{P}<0$. & & 0.001 & $<0.0001$ & & & \\
\hline \multirow{2}{*}{$92 \mathrm{df}$} & 0.203 & 0.2 & & 0.334 & 0.384 & & & \\
\hline & -0.203 & -0. & & -0.334 & -0.384 & & & \\
\hline
\end{tabular}

3

4 


\section{Table 4(on next page)}

Correlation coefficients for associations amongst measures of ELWL andleaf traits. Other details as in Table 3. 


\begin{tabular}{|c|c|c|c|c|c|c|c|c|}
\hline $\begin{array}{cr} & \text { Table 4. ELWL trait: } \\
\text { Trait: } & \text { Time period: }\end{array}$ & $\begin{array}{l}\text { ELWLW } \\
0-3 h\end{array}$ & $\begin{array}{l}\text { ELWLF } \\
0-3 h\end{array}$ & $\begin{array}{l}\text { ELWLD } \\
0-3 h\end{array}$ & $\begin{array}{l}\text { ELWLA } \\
0-3 \mathrm{~h}\end{array}$ & $\begin{array}{l}\text { ELWLW } \\
\text { 3-6h }\end{array}$ & $\begin{array}{l}\text { ELWLF } \\
3-6 \mathrm{~h}\end{array}$ & ELWLD & ELWLA \\
\hline ELWLW 0-3h & 1 & & & & & & & \\
\hline ELWLF 0-3h & 0.991 & 1 & & & & & & \\
\hline ELWLD 0-3h & 0.761 & 0.820 & 1 & & & & & \\
\hline ELWLA $0-3 \mathrm{~h}$ & 0.772 & 0.807 & 0.852 & 1 & & & & \\
\hline ELWLW 3-6h & 0.836 & 0.830 & 0.594 & 0.658 & 1 & & & \\
\hline ELWLF 3-6h & 0.209 & 0.206 & 0.120 & 0.209 & 0.687 & 1 & & \\
\hline ELWLD 3-6h & 0.138 & 0.169 & 0.298 & 0.299 & 0.581 & 0.925 & 1 & \\
\hline ELWLA 3-6h & 0.174 & 0.195 & 0.231 & 0.406 & 0.620 & 0.923 & 0.932 & 1 \\
\hline \multirow{2}{*}{$\begin{array}{l}0-3 \mathrm{~h} \text { water loss } \\
\text { 3-6h water loss }\end{array}$} & 0.219 & 0.271 & 0.446 & 0.461 & 0.223 & 0.105 & 0.225 & 0.259 \\
\hline & -0.059 & -0.029 & 0.078 & 0.169 & 0.346 & 0.712 & 0.741 & 0.773 \\
\hline Leaf length & -0.406 & -0.371 & -0.139 & -0.212 & -0.340 & -0.108 & 0.010 & -0.020 \\
\hline Leaf width & -0.231 & -0.219 & -0.170 & -0.185 & -0.135 & 0.028 & 0.016 & 0.012 \\
\hline Leaf area & -0.385 & -0.359 & -0.199 & -0.250 & -0.279 & -0.036 & 0.023 & -0.001 \\
\hline Leaf lamina thickness & -0.258 & -0.224 & -0.132 & -0.016 & -0.096 & 0.118 & 0.162 & 0.221 \\
\hline Leaf midrib thickness & -0.351 & -0.326 & -0.187 & -0.084 & -0.248 & -0.013 & 0.077 & 0.123 \\
\hline Leaf initial FW (0h) & -0.381 & -0.336 & -0.061 & -0.035 & -0.282 & -0.032 & 0.106 & 0.132 \\
\hline Leaf DW & -0.376 & -0.365 & -0.304 & -0.176 & -0.238 & 0.010 & -0.001 & 0.095 \\
\hline Leaf initial $\mathrm{FW} / \mathrm{cm}^{2}$ & -0.377 & -0.327 & -0.027 & -0.015 & -0.284 & -0.037 & 0.120 & 0.136 \\
\hline \multirow[t]{2}{*}{ Stomatal number/unit area } & 0.034 & 0.013 & -0.119 & -0.049 & 0.116 & 0.159 & 0.035 & 0.097 \\
\hline & 00.05 & $P<0.01$ & $P<0.001$ & $P<0.0001$ & & & & \\
\hline \multirow{2}{*}{$92 \mathrm{df}$} & 0.203 & 0.264 & 0.334 & 0.384 & & & & \\
\hline & -0.203 & -0.264 & -0.334 & -0.384 & & & & \\
\hline
\end{tabular}

2 


\section{Table 5 (on next page)}

Associations of yield/plant and drought-induced yieldreduction with measures of ELWL (a) and with leaf four traits (b). Other details as in Table 3. 
1 A)

\begin{tabular}{|l|cccc|cccc|}
\hline ELWL trait: & ELWLW & ELWLF & ELWLD & ELWLA & ELWLW & ELWLF & ELWLD & ELWLA \\
Yield trait: Time period: & $0-3 \mathrm{~h}$ & $0-3 \mathrm{~h}$ & $0-3 \mathrm{~h}$ & $0-3 \mathrm{~h}$ & $3-6 \mathrm{~h}$ & $3-6 \mathrm{~h}$ & $3-6 \mathrm{~h}$ & $3-6 \mathrm{~h}$ \\
\hline Yield/plant - control & -0.216 & -0.195 & -0.173 & -0.304 & -0.103 & 0.055 & 0.058 & -0.017 \\
Yield/plant - droughted & -0.318 & -0.290 & -0.133 & -0.242 & -0.212 & 0.007 & 0.102 & 0.031 \\
Ratio drought/control & -0.123 & -0.120 & 0.020 & 0.048 & -0.127 & -0.050 & 0.044 & 0.047 \\
Yield/plant at 7 g/plant & -0.327 & -0.300 & -0.155 & -0.351 & -0.233 & 0.000 & 0.074 & -0.062 \\
Yield/plant at 2 g/plant & -0.306 & -0.283 & -0.184 & -0.317 & -0.145 & 0.122 & 0.167 & 0.063 \\
\hline
\end{tabular}

2

$3 \mathrm{~B})$

\begin{tabular}{|l|cccccccc|}
\hline \multicolumn{1}{|c}{ Leaf trait: } & $\begin{array}{c}\text { Leaf } \\
\text { length }\end{array}$ & $\begin{array}{c}\text { Leaf } \\
\text { width }\end{array}$ & $\begin{array}{c}\text { Leaf } \\
\text { area }\end{array}$ & $\begin{array}{c}\text { Lamina } \\
\text { thickness }\end{array}$ & $\begin{array}{c}\text { Midrib } \\
\text { thickness }\end{array}$ & $\begin{array}{c}\text { Initial } \\
\text { FW }\end{array}$ & $\begin{array}{c}\text { Leaf } \\
\text { DW }\end{array}$ & $\begin{array}{c}\text { Stomatal } \\
\text { number }\end{array}$ \\
\hline Yield/plant - control & 0.304 & 0.309 & 0.373 & 0.211 & 0.108 & 0.260 & 0.288 & -0.079 \\
Yield/plant - droughted & 0.399 & 0.142 & 0.326 & 0.183 & 0.175 & 0.315 & 0.248 & -0.231 \\
Ratio drought/control & 0.043 & -0.185 & -0.084 & -0.027 & 0.058 & 0.024 & -0.073 & -0.149 \\
Yield/plant at 7 g/plant & 0.383 & 0.300 & 0.415 & 0.158 & 0.182 & 0.324 & 0.280 & -0.204 \\
Yield/plant at 2 g/plant & 0.250 & 0.273 & 0.318 & 0.247 & 0.144 & 0.242 & 0.230 & -0.088 \\
\hline
\end{tabular}

4

\begin{tabular}{|crrrc|}
\hline \multirow{2}{*}{$92 \mathrm{df}$} & $\mathrm{P}<0.05$ & $\mathrm{P}<0.01$ & $\mathrm{P}<0.001$ & $\mathrm{P}<0.0001$ \\
& 0.203 & 0.264 & 0.334 & 0.384 \\
& -0.203 & -0.264 & -0.334 & -0.384 \\
\hline
\end{tabular}

5 


\section{Table 6(on next page)}

Ratios between yield/plant for the chose CSDH lines with chose traits.

Ratios between yield/plant for the $10 \mathrm{CSDH}$ lines with the lowest ELWLW ${ }_{0-3 h}$ and with the highest leaf length and yield/plant for both the $10 \mathrm{CSDH}$ lines with the highest ELWLW 0.3h $_{\text {and }}$ anth the lowest leaf length and the remaining $84 \mathrm{CSDH}$ lines for five measures of yield/plant. Significant differences ${ }^{\S}$ are indicated by ratios in bold italics, and ratios less than one are shown in red.

\$ Significance of differences in yield/plant between the 10 most favourable and 10 least favourable CSDH lines for the 52 trials, 19 control and 12 droughted trials were tested using a paired-sample $t$-test with trial means.

Significance of differences in yield/plant between the most favourable $10 \mathrm{CSDH}$ lines and the remaining 84 lines for the 52 trials, 19 control and 12 droughted trials were tested using two-way ANOVA, with experiments as replications.

Significance of differences in yield/plant between the 10 most favourable and both the 10 least favourable lines and the remaining 84 lines at site yields of 7 and $2 \mathrm{~g} /$ plant were tested using a two-sample $t$-test with equal variances.

$*, * *, * * *, * * * *$ Means of yield/plant for $10 \mathrm{CSDH}$ most favourable lines and either the 10 least favourable lines or the remaining 84 lines significantly different at $P<0.05,0.01,0.001,0.0001$, respectively. 


\begin{tabular}{|c|c|c|c|c|c|c|}
\hline Trait & Year & \begin{tabular}{|cc||} 
Mean of all & 52 \\
trials & \\
\end{tabular} & $\begin{array}{l}\text { Mean of } 19 \\
\text { control trials }\end{array}$ & $\begin{array}{c}\text { Mean of } 12 \\
\text { droughted trials }\end{array}$ & $\begin{array}{l}\text { Site yield of } \\
7 \mathrm{~g} / \text { plant }\end{array}$ & $\begin{array}{c}\text { Site yield of } \\
2 \mathrm{~g} / \mathrm{plant}\end{array}$ \\
\hline $\begin{array}{l}\text { ELWLW } 0-3 \mathrm{~h} \\
10 \text { lowest versus } \\
10 \text { highest lines }\end{array}$ & $\begin{array}{l}2007 \\
2008 \\
2009 \\
\text { mean } \\
\end{array}$ & $\begin{array}{l}1.172 * * * * \\
1.086 * * * * \\
1.140 * * * * \\
1.200 * * * *\end{array}$ & $\begin{array}{l}1.153 * * * * \\
1.103 * * * \\
1.103 * * * * \\
1.156 * * * * \\
\end{array}$ & $\begin{array}{c}1.221 * \\
1.052 \\
1.233 * * \\
1.252 * * \\
\end{array}$ & $\begin{array}{c}1.197 * \\
1.113 \\
1.109 \\
1.240 * * \\
\end{array}$ & $\begin{array}{c}1.114 \\
1.083 \\
1.141 * \\
1.151 * * \\
\end{array}$ \\
\hline $\begin{array}{c}\text { Leaf length } \\
10 \text { highest versus } 10 \\
\text { lowest lines }\end{array}$ & $\begin{array}{l}2007 \\
2008 \\
2009 \\
\text { mean }\end{array}$ & $\begin{array}{c}1.106 * \\
1.250 * * * * \\
1.193 * * * * \\
1.209 * * * *\end{array}$ & $\begin{array}{c}1.114 * * \\
1.294 * * * * \\
1.202 * * * * \\
1.238 * * * *\end{array}$ & $\begin{array}{l}1.219 \\
1.335 \\
1.247 \\
1.276 \\
\end{array}$ & $\begin{array}{c}1.046 \\
1.256 * * \\
1.142 \\
1.202 *\end{array}$ & $\begin{array}{c}1.078 \\
1.181 * * \\
1.163 * \\
1.170 * * \\
\end{array}$ \\
\hline $\begin{array}{c}\text { ELWLW } 0-3 \mathrm{~h} \\
10 \text { lowest versus } \\
84 \text { remaining lines }\end{array}$ & $\begin{array}{l}2007 \\
2008 \\
2009 \\
\text { mean }\end{array}$ & $\begin{array}{c}1.065 \\
1.004 \\
1.024 \\
1.0310 * * *\end{array}$ & $\begin{array}{c}1.048 \\
1.029 \\
1.011 \\
1.0290 * * * *\end{array}$ & $\begin{array}{c}1.083 \\
0.977 \\
1.030 \\
1.0300 \\
\end{array}$ & $\begin{array}{c}1.086 \\
1.025 \\
0.984 \\
1.0317 \\
\end{array}$ & $\begin{array}{r}1.041 \\
1.017 \\
1.036 \\
1.0313 * * \\
\end{array}$ \\
\hline $\begin{array}{c}\text { Leaf length } \\
10 \text { highest versus } \\
84 \text { remaining lines }\end{array}$ & $\begin{array}{l}2007 \\
2008 \\
2009 \\
\text { mean }\end{array}$ & $\begin{array}{c}0.978 \\
1.028 \\
1.054 \\
1.0200 \\
\end{array}$ & $\begin{array}{c}0.943 \\
1.024 \\
1.028 \\
0.9983 \\
\end{array}$ & $\begin{array}{c}1.026 \\
1.049 \\
1.077 \\
1.0507 * * \\
\end{array}$ & $\begin{array}{c}0.893 * * \\
0.976 \\
0.983 \\
0.9507\end{array}$ & $\begin{array}{c}0.993 \\
1.016 \\
1.040 \\
1.0163 \\
\end{array}$ \\
\hline
\end{tabular}

1 


\section{Table 7 (on next page)}

Correlation coefficients for associations between marker additive effect ratio (MAR) maximafor ELWL and constitutive leaf traits and MARs at the same QTL markers for measures of yield.

Constitutive leaf traits (QTLs listed in Table S1).

Significance level is indicated by the degree of shading. 


\begin{tabular}{|l|ccccccc|}
\hline Trait & No of QTLs & All yields (52) & Controls (19) & Droughted (12) & Drought/control & $7 \mathrm{~g} / \mathrm{plant}$ & $2 \mathrm{~g} / \mathrm{plant}$ \\
\hline ELWLW (0-3h) & 25 & 0.042 & 0.305 & -0.445 & -0.800 & 0.231 & 0.057 \\
ELWLA (0-3h) & 30 & -0.399 & 0.304 & -0.574 & -0.365 & -0.680 & 0.177 \\
ELWLW (3-6h) & 24 & -0.001 & 0.267 & -0.402 & -0.703 & -0.205 & 0.254 \\
ELWLA (3-6h) & 25 & -0.078 & -0.048 & -0.243 & -0.304 & -0.317 & -0.362 \\
\hline Leaf length & 26 & 0.704 & 0.502 & 0.848 & 0.342 & 0.771 & 0.410 \\
Leaf width & 24 & 0.639 & 0.533 & 0.416 & -0.226 & 0.705 & 0.505 \\
Leaf area & 26 & 0.579 & 0.422 & 0.639 & 0.227 & 0.665 & 0.361 \\
Midrib thickness & 20 & 0.167 & 0.110 & 0.348 & 0.250 & 0.437 & 0.059 \\
\hline
\end{tabular}

\section{Shading for significance level} according to df. 


\section{Figure $\mathbf{1}$ (on next page)}

Single marker analysis (SMA) of additive effects.

SMA for ELWLW 0-3h, ELWLA 0-3h, ELWLW 3-6h and ELWLA 3-6h expressed as ratios of the minimum significant additive effect with marker additive ratios (MARs) meaned across the three experiments. Lines join MARs for adjacent markers. The four ELWL traits are grouped according to time period. Continuous coloured lines join MARs for adjacent markers. Markers are ordered sequentially left to right from chromosome 1A short arm to chromosome 7D long arm. Positive MARs indicate alleles with increasing effects from Chinese Spring. Negative MARs indicate alleles with increasing effects from SQ1. Short arrows, coloured according to ELWL trait, identify QTL peaks described in Table S1. Arrowheads indicate coincidence of QTLs for ELWLW 0-3h and ELWLW 3-6h (blue), and ELWLA 0-3h and ELWLA 3-6h (red). 
Chromosome

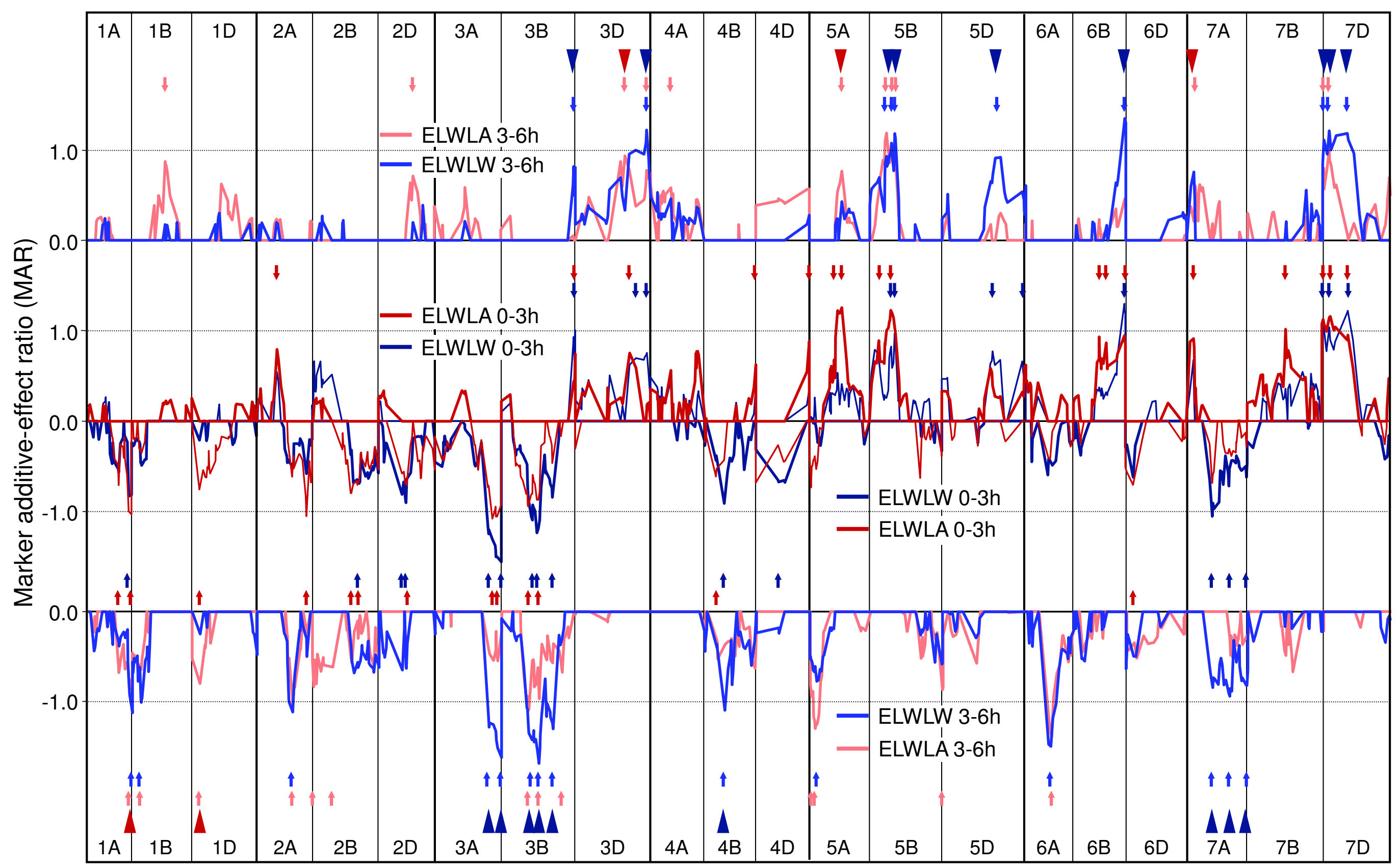




\section{Figure 2 (on next page)}

Single marker analysis (SMA) of additive effects for leaf length, leaf width, leafarea and leaf midrib thickness.

SMA of additive effects for leaf length, leaf width, leaf area and leaf midrib thickness, expressed as ratios of the minimum significant additive effect with marker additive ratios (MARs) meaned across the three experiments. Leaf traits are grouped according to similarity of their MARs (leaf length and midrib thickness, leaf width and leaf area). Short arrows, coloured according to leaf trait, identify QTL peaks described in Table S1. Other details as described for Figure 1. 


\section{Chromosome}

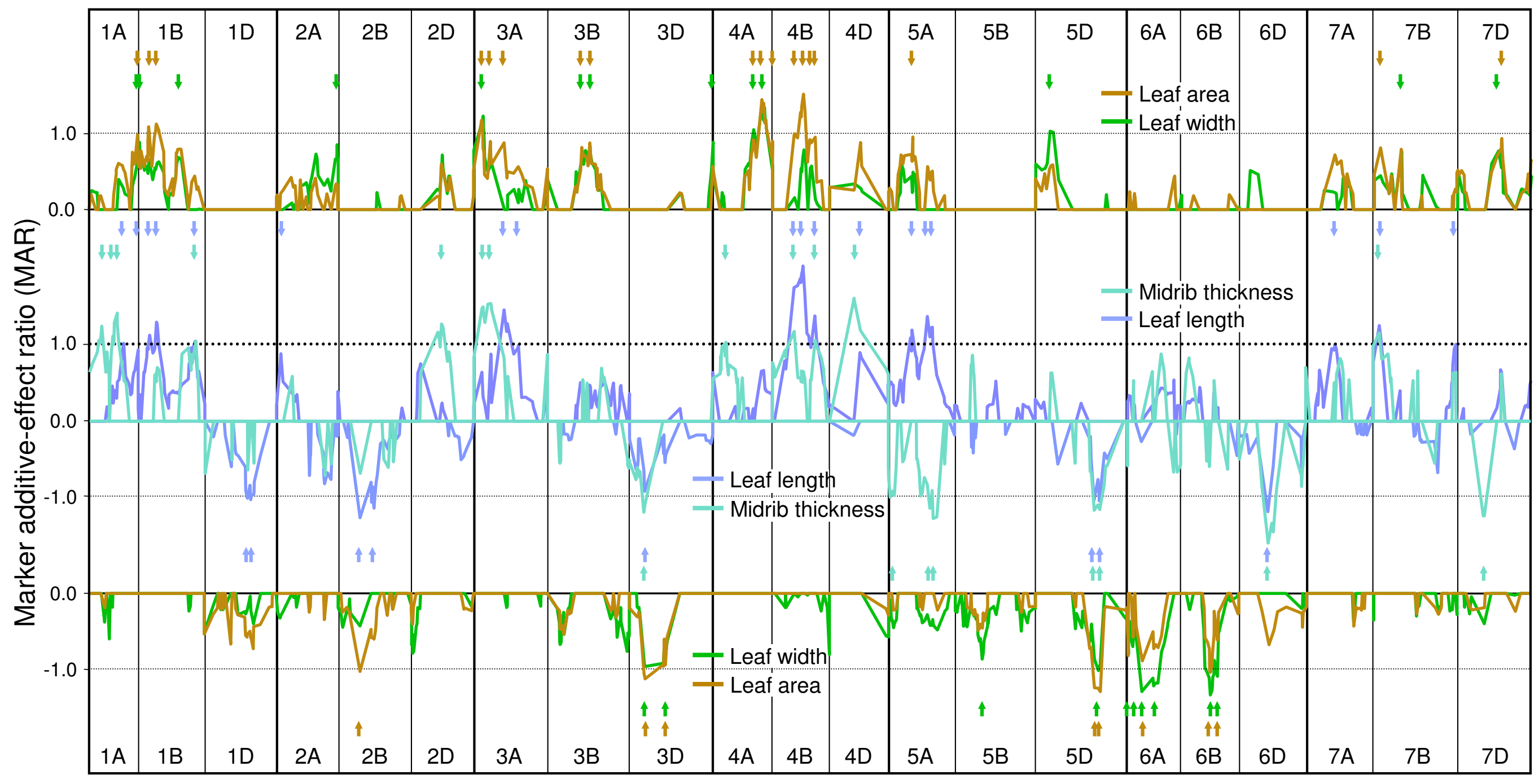




\title{
Figure 3 (on next page)
}

Single marker analysis (SMA) of additive effects for both ELWL and leaf traits combined.

\begin{abstract}
A) positive marker additive ratios (MARs) with increasing alleles from Chinese Spring, and B) negative MARs with increasing alleles from SQ1. Note, because of the negative correlations between ELWL and leaf traits (Table 4), ELWL traces are inverted to ease comparison amongst traits. Arrowheads, coloured according to ELWL trait, indicate coincidence between ELWL and leaf trait QTLs. Other details as described for Figure 1.
\end{abstract}




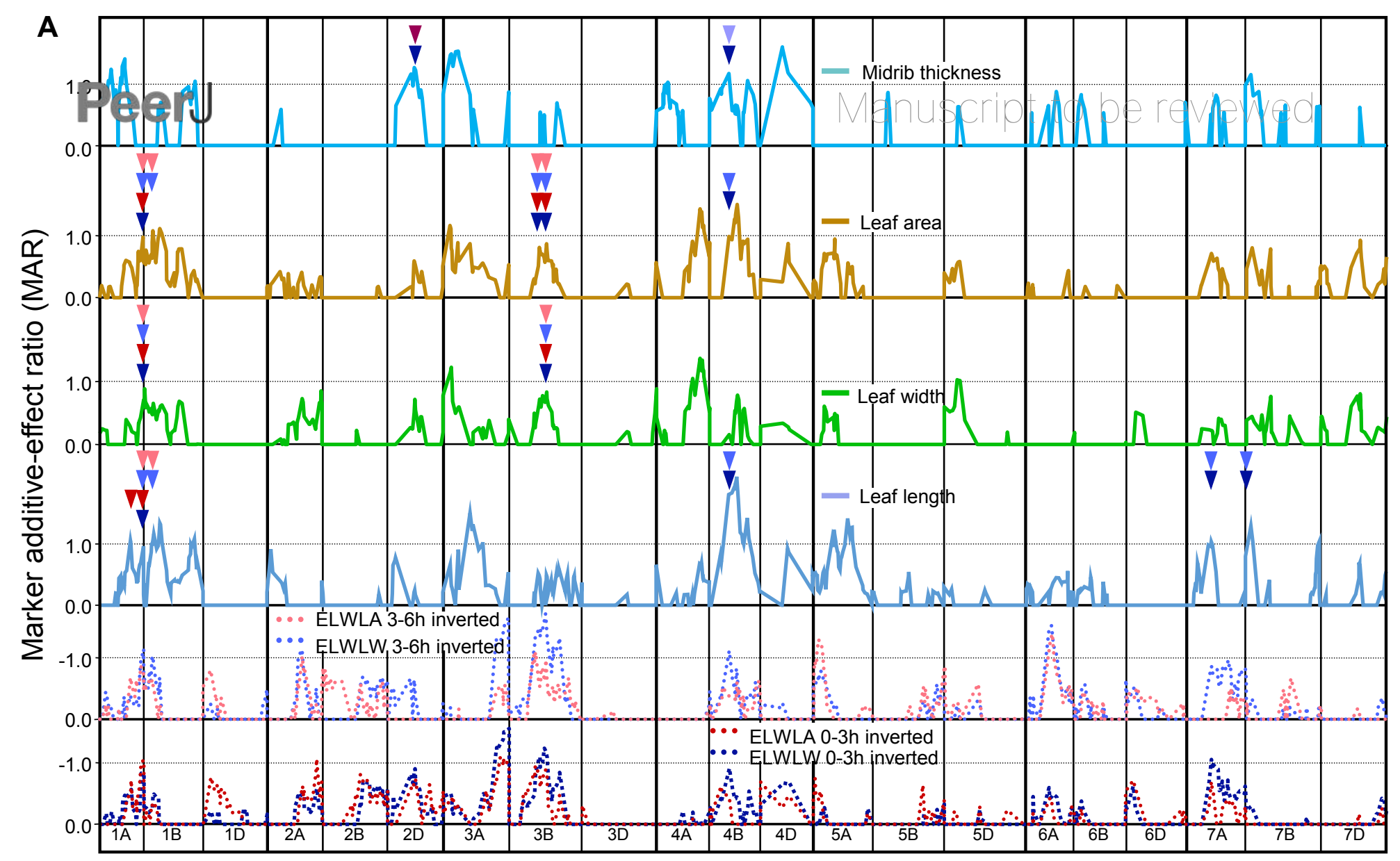

Chromosome

B

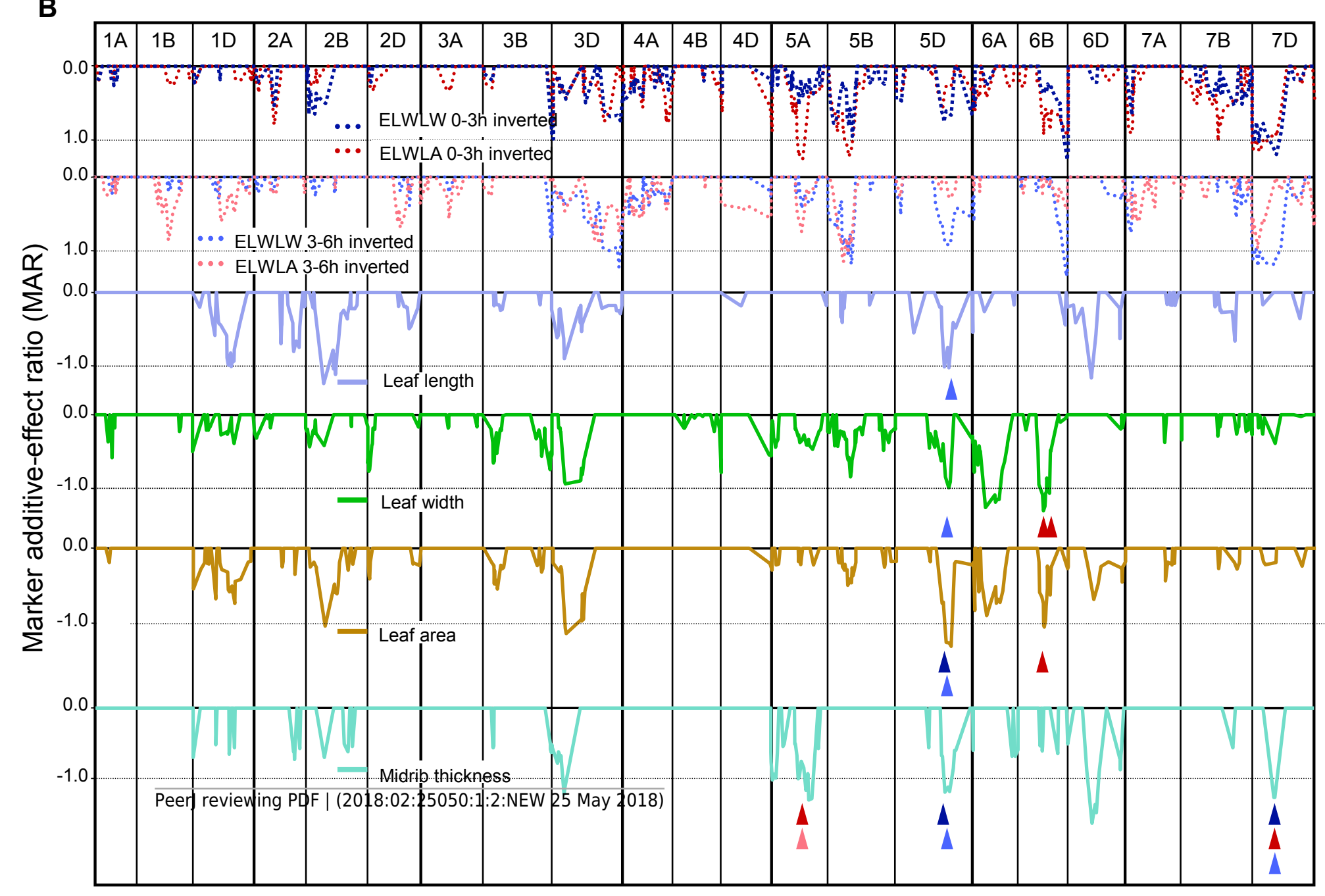




\section{Figure 4 (on next page)}

Single marker analysis (SMA) of additive effects.

SMA expressed as marker additive ratios (MARs), for all 52 yield trials, control, droughted, yields at site yields of $7 \mathrm{tha-} 1$ and $2 \mathrm{t}$ ha-1, droughted/control yield ratio, as well as ELWLWO3h and ELWLA0-3h (both inverted): A) positive marker additive ratios (MARs) with increasing alleles from Chinese Spring, and B) negative MARs with increasing alleles from SQ1. MARs for mean 52-trial yield, control and droughted yields were calculated using Method 1. For control yield, droughted yield, yields at site yields of $7 \mathrm{t}$ ha- $1,2 \mathrm{t}$ ha- 1 and droughted/control yield ratio, to aid clarity, only MARs $\geq 0.5$ are shown. Coloured arrows indicate yield MAR peaks $>1$ coincident with peaks present for 52 -trial MAR data. For 52-trial MAR data, 0.5 is equivalent to MARs greater than 1.0 in ca. $20 \%$ of trials and 0.35 is equivalent to MARs greater than 1.0 in ca. $10 \%$ of trials. Other details as described for Figure 1. 


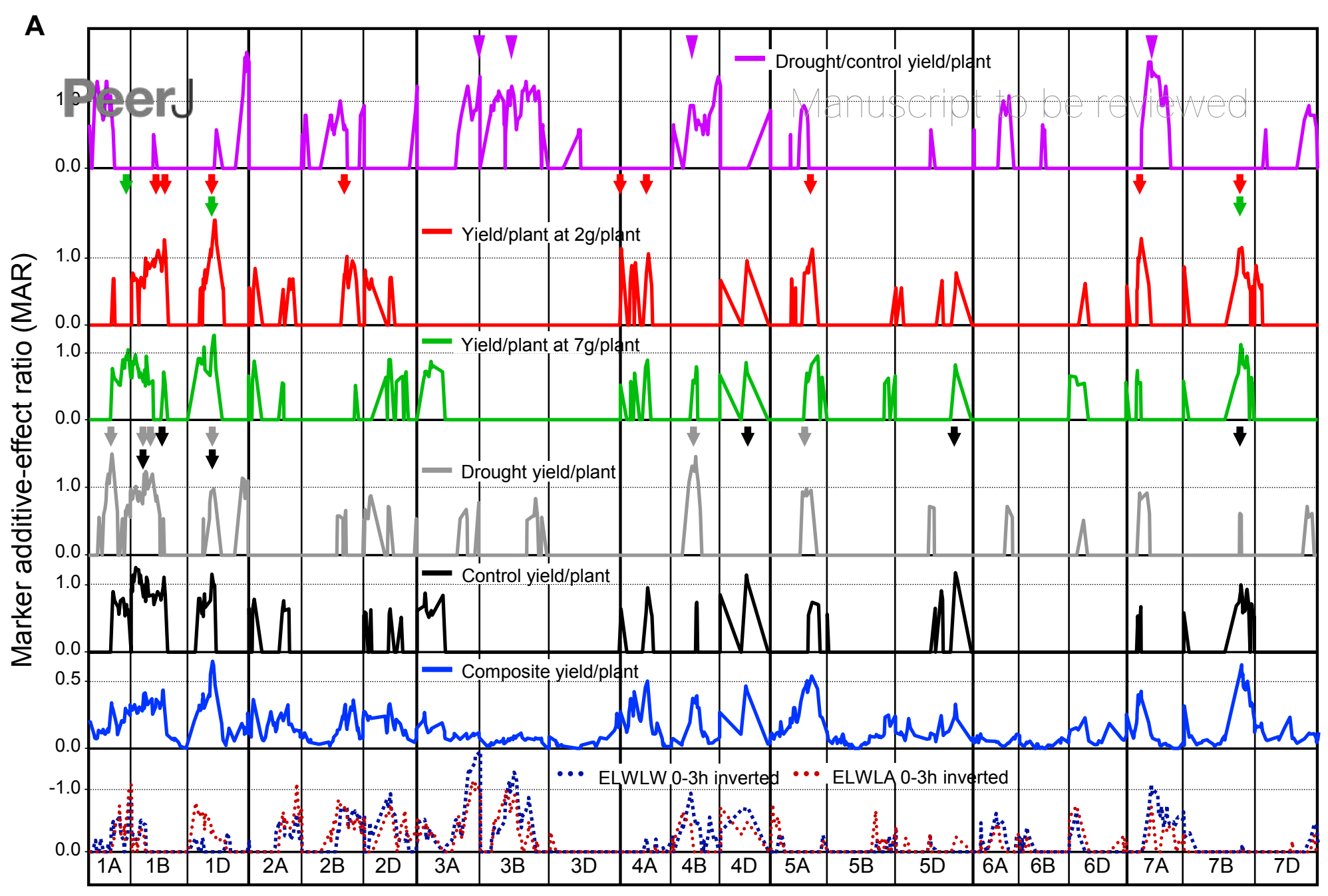

Chromosome

B

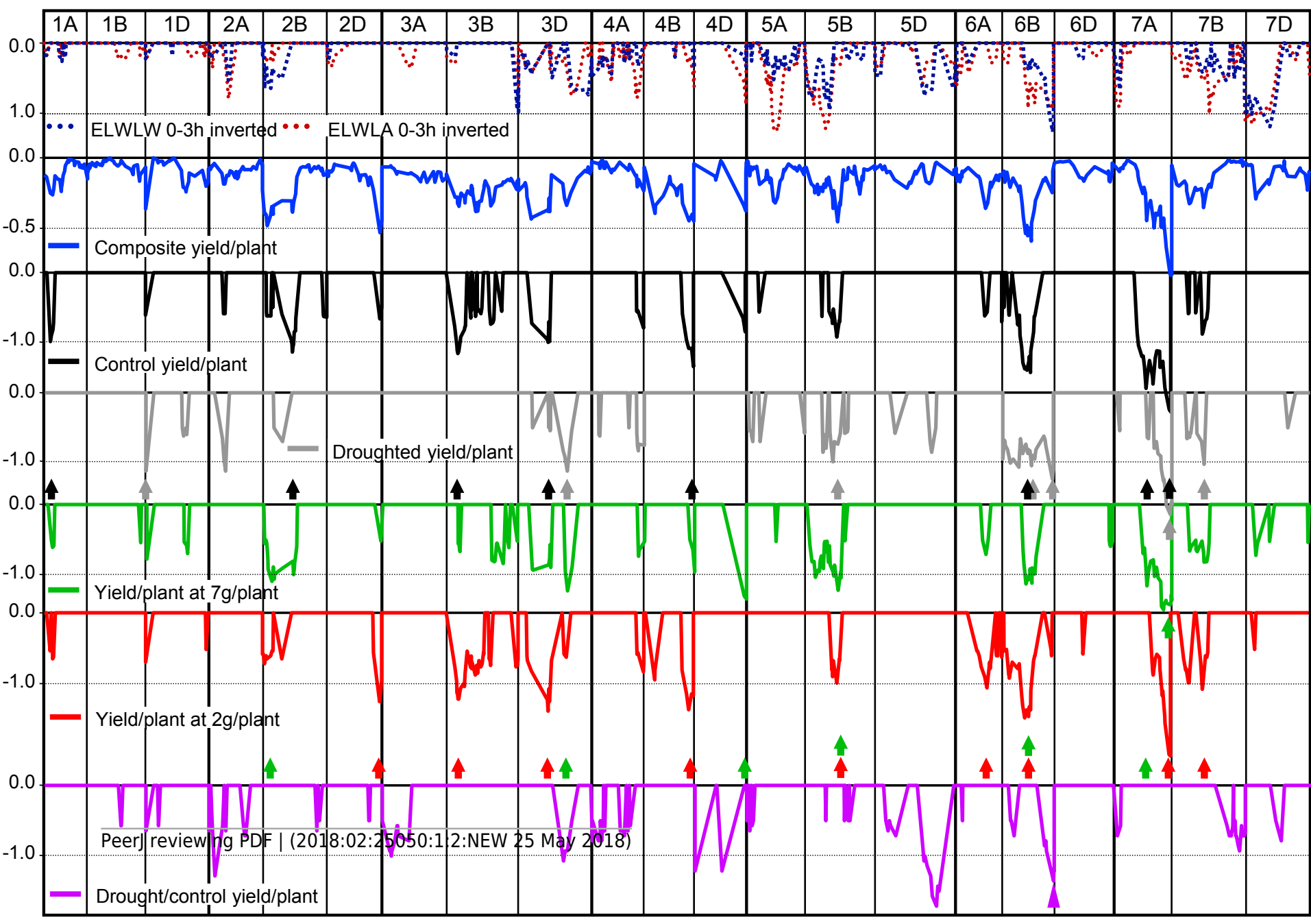

